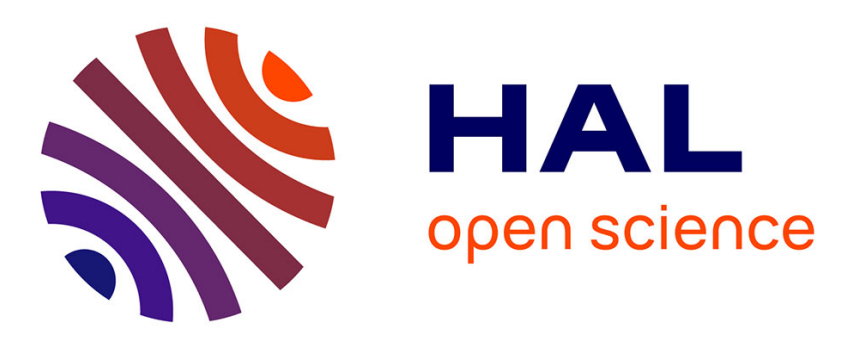

\title{
The RNA-Binding Protein RBPMS2 Regulates Development of Gastrointestinal Smooth Muscle
}

Cécile Notarnicola, Caroline Rouleau, Ludovic Le Guen, Anne Virsolvy, Sylvain Richard, Sandrine Faure, Pascal de Santa Barbara

\section{- To cite this version:}

Cécile Notarnicola, Caroline Rouleau, Ludovic Le Guen, Anne Virsolvy, Sylvain Richard, et al.. The RNA-Binding Protein RBPMS2 Regulates Development of Gastrointestinal Smooth Muscle. Gastroenterology, 2012, 143 (3), pp.687-697.e9. 10.1053/j.gastro.2012.05.047 . hal-02542417

\section{HAL Id: hal-02542417 \\ https://hal.umontpellier.fr/hal-02542417}

Submitted on 14 Apr 2020

HAL is a multi-disciplinary open access archive for the deposit and dissemination of scientific research documents, whether they are published or not. The documents may come from teaching and research institutions in France or abroad, or from public or private research centers.
L'archive ouverte pluridisciplinaire HAL, est destinée au dépôt et à la diffusion de documents scientifiques de niveau recherche, publiés ou non, émanant des établissements d'enseignement et de recherche français ou étrangers, des laboratoires publics ou privés. 


\title{
The RNA-Binding Protein RBPMS2 Regulates Development of Gastrointestinal Smooth Muscle
}

\author{
CÉCILE NOTARNICOLA, , CAROLINE ROULEAU, ${ }^{*, \neq}$ LUDOVIC LE GUEN, ${ }^{\star}$ ANNE VIRSOLVY, SYLVAIN RICHARD, \\ SANDRINE FAURE, ${ }^{*}$ and PASCAL DE SANTA BARBARA*
}

*INSERM U1046, Université Montpellier 1, Université Montpellier 2, Montpellier; and ${ }^{\ddagger}$ CHRU Montpellier, Service d'Anatomie Pathologique, Montpellier, France

BACKGROUND \& AIMS: Gastrointestinal development requires regulated differentiation of visceral smooth muscle cells (SMCs) and their contractile activities; alterations in these processes might lead to gastrointestinal neuromuscular disorders. Gastrointestinal SMC development and remodeling involves post-transcriptional modification of messenger RNA. We investigated the function of the RNA-binding protein for multiple splicing 2 (RBPMS2) during normal development of visceral smooth muscle in chicken and expression of its transcript in human pathophysiological conditions. METHODS: We used avian replication-competent retroviral misexpression approaches to analyze the function of RBPMS2 in vivo and in primary cultures of chicken SMCs. We analyzed levels of RBPMS2 transcripts in colon samples from pediatric patients with Hirschsprung's disease and patients with chronic pseudo obstruction syndrome (CIPO) with megacystis. RESULTS: RBPMS2 was expressed strongly during the early stage of visceral SMC development and quickly down-regulated in differentiated and mature SMCs. Misexpression of RBPMS2 in differentiated visceral SMCs induced their dedifferentiation and reduced their contractility by up-regulating expression of Noggin, which reduced activity of bone morphogenetic protein. Visceral smooth muscles from pediatric patients with CIPO expressed high levels of RBPMS2 transcripts, compared with smooth muscle from patients without this disorder. CONCLUSIONS: Expression of RBPMS 2 is present in visceral SMC precursors. Sustained expression of RBPMS 2 inhibits the expression of markers of SMC differentiation by inhibiting bone morphogenetic protein activity, and stimulates SMC proliferation. RBPMS2 transcripts are up-regulated in patients with CIPO; alterations in RBPMS2 function might be involved in digestive motility disorders, particularly those characterized by the presence of muscular lesions (visceral myopathies).

Keywords: Developmental Biology; RNA-Binding Protein; Gastrointestinal Tract; Smooth Muscle Contraction.

$\mathrm{M}$ otility of the digestive tract is ensured by the contraction of visceral smooth muscles under the control of the autonomous enteric nervous system (ENS) and the interstitial cells of Cajal (ICC). ${ }^{1-3}$ Dysfunction of just one of these cell types can lead to the development of gastrointestinal neuromuscular disorders in infants and adults. ${ }^{4,5}$ Many studies have investigated the role of ENS damage in these diseases and shown that ENS absence caused by precocious differentiation or blockage of its migration triggers Hirschsprung disease (HSCR). ${ }^{2-4}$ Alteration of ICC number, which perturbs the ICC network, also has been observed in different digestive motility disorders. ${ }^{4,6}$ Until now, dysfunction of the downstream effector (visceral smooth muscle) rarely was investigated in gastrointestinal neuromuscular disorders. ${ }^{4,6,7}$ Specifically, muscular lesions, classified as visceral myopathies, have been observed mainly in patients with chronic intestinal pseudo-obstruction (CIPO). However, the systematic analysis of muscular alterations has been overlooked mainly because of the poor knowledge of the molecular mechanisms involved in visceral smooth muscle cell (SMC) homeostasis. The limited number of valuable SMC markers is also an obstacle to the clinical investigation of visceral smooth muscle integrity in these motility disorders.

More is known about the molecular control of visceral SMCs during embryonic development. Visceral SMCs originate from the splanchnopleural mesoderm that forms the primitive visceral mesenchyme via activation of the hedgehog/bone morphogenetic protein (BMP) pathway. ${ }^{2}$ Differentiation of visceral mesenchymal cells into visceral SMCs can be visualized first through their elongation and clustering and later by the expression of SMCspecific lineage markers, such as $\alpha$-smooth muscle actin $(\alpha \mathrm{SMA})$, smooth muscle protein-22 (SM22), calponin, smoothelin, and smooth muscle myosin heavy chain (SM$\mathrm{MHC}$ ), which precedes contractile function. ${ }^{8}$ Only a few studies have investigated the molecular mechanisms controlling visceral mesenchyme differentiation into SMCs.

Abbreviations used in this paper: $\alpha \mathrm{SMA}, \alpha$-smooth muscle actin; BMP, bone morphogenetic protein; CIPO, chronic intestinal pseudoobstruction; DMEM, Dulbecco's modified Eagle medium; E, embryonic day; ENS, enteric nervous system; FHL2, four and a half LIM domains 2; GFP, green fluorescent protein; HSCR, Hirschsprung disease; ICC, interstitial cells of Cajal; mRNA, messenger RNA; P-AKT, phosphorylated AKT; PH3, phospho-histone H3-Ser10; PSMAD, phosphorylated SMAD; QPCR, quantitative polymerase chain reaction; RBPMS2, RNA-binding protein for multiple splicing 2; RBP, RNA-binding protein; RCAS, Replication-Competent Avian leucosis Sarcoma virus; RRM, RNA recognition motif; SHH, sonic hedgehog; SMC, smooth muscle cell; SM-MHC, smooth muscle myosin heavy chain; SM22, smooth muscle protein-22; SRF, serum response factor. 
Endodermal hedgehog signaling activation promotes visceral mesenchyme growth through expression of the Patched receptor and of $B m p 4$ that drives its differentiation into SMCs. ${ }^{9}$ Aberrant modulation of BMP activity induces visceral smooth muscle disorganization. ${ }^{10}$ The fibroblast growth factor signaling pathway also is activated in visceral mesenchymal cells and is specifically down-regulated during visceral SMC differentiation, which is inhibited by sustained activation of the fibroblast growth factor pathway in vivo. ${ }^{11}$ Although a substantial body of works has investigated visceral SMC development, the specific molecular mechanisms controlling its differentiation remain to be clarified.

Besides transcription, which represents the first step of gene expression, many post-transcriptional events regulate the final fate of messenger RNAs (mRNAs) in eukaryotic cells and determine their spatiotemporal pattern of expression. RNA-protein complexes control multiple steps of this process, including mRNA cellular localization, splicing, translational regulation, or mRNA degradation. ${ }^{12}$ These complexes contain specific RNA-binding proteins (RBPs) that play important roles during development. The RNA recognition motif (RRM) proteins, a large RBP family involved in regulating RNA metabolism, are expressed in a tissue-specific manner, suggesting that they may participate in distinct developmental processes. ${ }^{13}$ Moreover, postregulatory RNA events are involved in the control of differentiation and remodeling of smooth muscle tissues, such as heart and vessels, ${ }^{14}$ suggesting that visceral smooth muscle development and plasticity could be regulated similarly. RNA-binding protein for multiple splicing 2 (RBPMS2), a member of the RRM family, is expressed in vertebrate heart and gastrointestinal tract. ${ }^{13,15}$ By using a microarray approach to identify modulators of visceral SMC development, we found that RBPMS2 is expressed during the early stages of chick SMC development (unpublished data). ${ }^{11}$

Here, we investigated RBPMS2 function and mechanism of action during visceral SMC development and assessed its transcript expression in colon from patients with digestive motility disorders. We show that RBPMS2 is an early marker of visceral SMC precursors and that RBPMS2 misexpression in differentiated SMCs increases proliferation and hinders their contractile function. The RBPMS2-dependent contractile differentiation defect is mediated by inhibition of BMP signaling through up-regulation of Noggin, its major inhibitor. These results indicate that ectopic RBPMS2 expression in vivo and in primary cultured SMCs phenocopies the alteration of the contractile function observed in patients with visceral myopathy.

\section{Materials and Methods}

\section{Chick Embryonic Gastrointestinal Tissues}

Fertilized White Leghorn eggs from Haas Farm (Kaltenhouse, France) were incubated at $38^{\circ} \mathrm{C}$ in humidified incubators. Gastrointestinal tissues from chick embryos were dissected as described. ${ }^{16}$

\section{Human Colon Samples}

Tissue samples from pediatric patients ( 1 month to 1 year) were from the collection of the Lapeyronie Hospital (Montpellier, France) as previously described. ${ }^{17}$ Control samples were right colon specimens from 3 neonates who underwent ileocolic resection for congenital cystic duplication of the terminal ileum. Full-thickness, large-bowel specimens were obtained after rectosigmoidectomy from 3 patients diagnosed with HSCR or 3 patients diagnosed with slow-transit constipation without HSCR and with megacystis (CIPO patients).

\section{Avian Retroviral Misexpression System}

Myc-tagged chick full-length RBPMS2 was cloned into the Replication-Competent Avian Leucosis Sarcoma virus strain A (RCAS[A]) vector to produce replication-competent retroviruses that express Myc-RBPMS2. The RCAS(A)-Noggin and RCAS stain $B$ with green fluorescence protein coding region (RCAS[B]GFP) retroviral constructs were described previously. ${ }^{11,16}$ Retroviral constructs were transfected into the DF-1 chicken fibroblast cell line (ATCC-LGC) to produce retroviruses. Retroviruses were injected into the splanchnopleural mesoderm of stage-10 chicken embryos to target the stomach mesenchyme. ${ }^{10,16}$ Eggs then were placed at $38^{\circ} \mathrm{C}$ until harvested.

\section{Primary Cultured SMCs and Analysis}

Primary cultures from embryonic day 15 (E15) gizzard muscle were prepared as described. ${ }^{18}$ Briefly, the tunica muscularis carefully was separated from the serosa and tunica mucosa before collagenase dissociation. Isolated cells were cultured in Dulbecco's modified Eagle medium (DMEM) in the presence of $0.2 \%$ bovine serum albumin and $5 \mu \mathrm{g} / \mathrm{mL}$ insulin in Matrigelcoated plates (VWR, Fontenay-sous-Bois cedex, France) to maintain the cell differentiation status $(>95 \%$ of isolated cells were Desmin- and $\alpha$ SMA-positive, data not shown). Differentiated SMCs then were infected with different retroviruses and maintained in culture for 1-7 days. In our conditions, avian retroviruses have a high tropism to infect SMCs and low tropism for enteric neurons (Supplementary Figure 1). SMC contractility was monitored with a Nikon inverted microscope and cells were imaged before and after treatment with $10^{-3} \mathrm{~mol} / \mathrm{L}$ carbachol (Sigma, France), a muscarinergic agonist, as previously published. ${ }^{18}$ In rescue experiments, differentiated SMCs infected with retroviruses during 3 days were treated with $20 \mathrm{ng} / \mathrm{mL}$ of purified BMP4 (Humanzyme, Chicago, IL) for 4 days.

\section{Isometric Tension Measurement During Contractile Activity}

E15 gizzards were cut at the level of the ventral and dorsal tendons to avoid damaging the muscular bundles. ${ }^{11}$ The right part of the organ connected to the duodenum was used for the measurements (control, $\mathrm{n}=23$; RBPMS2 misexpression, $\mathrm{n}=$ 21). Organs were mounted between 2 stainless steel hooks and placed in an organ bath filled with Tyrode-HEPES solution with $2.5 \mathrm{mmol} / \mathrm{L} \mathrm{CaCl}_{2}$ continuously bubbled with $95 \% \mathrm{O}_{2} / 5 \% \mathrm{CO}_{2}$ and maintained at $37^{\circ} \mathrm{C}$. Changes in isometric tension were recorded using an IT1-25 force transducer and an IOX computerized system (EMKA Technologies, Paris, France). Gizzards initially were stretched at a resting tension of $0.5 \mathrm{~g}$ and, after a 60-minute equilibration period, contraction was induced with cumulative doses of carbachol $\left(10^{-6}\right.$ to $\left.10^{-3} \mathrm{~mol} / \mathrm{L}\right)$. Effects were evaluated by measuring the maximum tension, and data were expressed as changes relative to the basal tension (contraction in g) for $10^{-4} \mathrm{~mol} / \mathrm{L}$ carbachol concentration. 

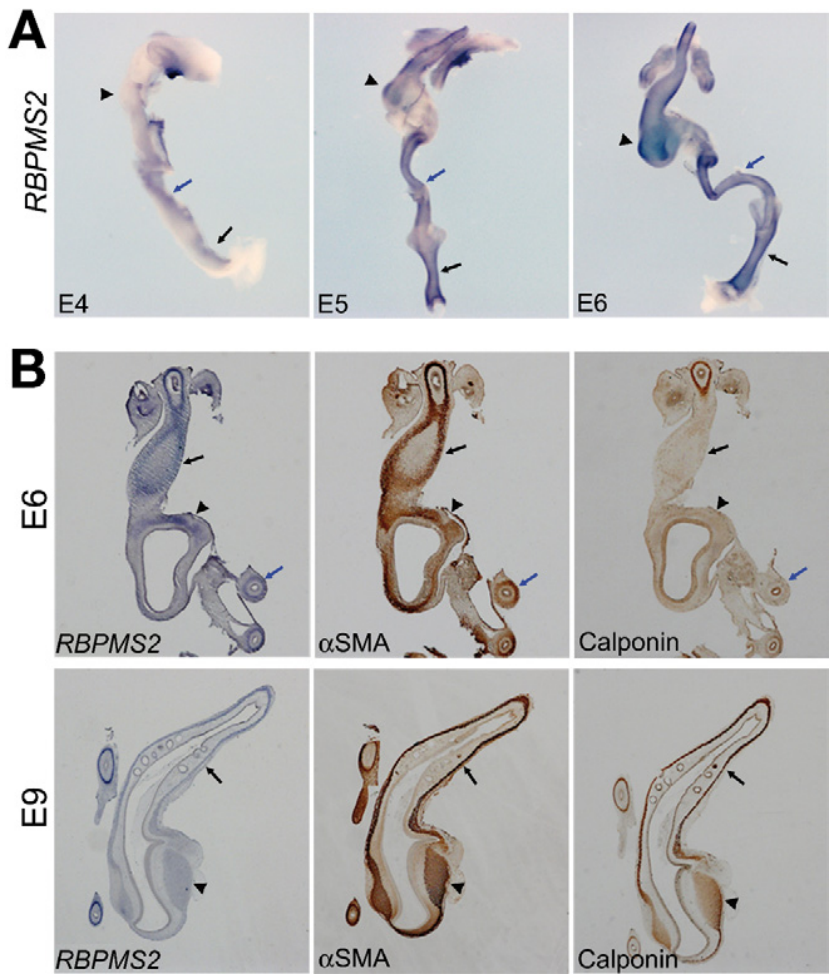

Figure 1. Dynamic expression of RBPMS2 in chick gastrointestinal mesenchyme. (A) Whole-mount in situ hybridization of E4, E5, and E6 gastrointestinal tracts using the RBPMS2 riboprobe. Arrows, arrowheads, and blue arrows indicate the colon, developing stomach, and small intestine, respectively. (B) Serial longitudinal sections of E6 (upper pane/s) and E9 (lower pane/s) stomachs analyzed by in situ hybridization with the RBPMS2 riboprobe and by immunohistochemistry with anti$\alpha \mathrm{SMA}$ and anticalponin antibodies. Arrows, arrowheads, and blue arrows indicate the anterior glandular stomach, posterior muscular stomach, and duodenum, respectively.

\section{Western Blotting, In Situ Hybridization, Immunodetection, Microarray Experiments, Quantitative Polymerase Chain Reaction}

See the Supplementary Materials and Methods section for more detail.

\section{Results}

\section{Dynamic Expression of RBPMS2 in Chick Gastrointestinal Mesenchyme}

To determine the role of RBPMS 2 in the digestive visceral smooth muscle, first we analyzed its expression during chick gastrointestinal tract development. RBPMS2 started to be expressed at embryonic day 4 (E4), an early stage of gastrointestinal tract development, in the regions of the future stomach, midgut, and colon (Figure 1A). At E5, RBPMS2 was expressed strongly in the developing stomach, small intestine, and colon, with the exception of the cecum (Figure 1A). Additional expression was observed in the developing lungs. At E6, RBPMS2 transcripts accumulated in the stomach, small intestine, and colon (Figure 1A). RBPMS2 expression was temporally and spatially comparable with that of $\alpha S M A$, the earliest known SMC marker, which is expressed in the developing and differentiated visceral smooth musculature (Supplementary Figure 2). By using paraffin sections we showed that, at E6, RBPMS2 and $\alpha$ SMA expression overlapped in the undifferentiated visceral mesenchyme (Figure 1B, upper panels). However, after visceral smooth muscle differentiation (E9), RBPMS2 expression rapidly decreased in the smooth muscle layer, whereas calponin (which is a marker of differentiated SMCs) expression increased (Figure 1B, lower panels). In summary, RBPMS2 expression was highest in undifferentiated visceral mesenchymal cells and progressively decreased with muscle differentiation, thus identifying it as an early marker of visceral smooth muscle precursor cells.

\section{Sustained RBPMS2 Expression Alters Gastrointestinal Development, SMC Differentiation, and Contractile Function}

To investigate RBPMS2 function, we maintained RBPMS2 expression throughout visceral muscle development and differentiation by using an avian replicationcompetent retroviral misexpression system that allows in vivo targeting of specific genes in the stomach mesenchyme. ${ }^{11,16}$ Sustained RBPMS2 expression resulted in a dramatic alteration of the stomach morphology (Figure $2 A)$. Specifically, the proventriculus, which is the glandular part of the chick stomach (Figure $2 A$, white arrowheads), was hypertrophied, whereas the gizzard (the muscular part, Figure $2 A$, white arrows) was denser and malformed in comparison with controls that overexpressed GFP alone (Figure 2A). However, sustained RBPMS2 expression did not affect stomach development and patterning, as revealed by the normal expression of the mesenchymal marker BARX1 and of the endodermal marker sonic hedgehog $(S H H)$ in RBPMS2 misexpressing stomachs (Figure $2 B$ ). Similarly, the determination of visceral SMCs was not affected because positive $\alpha$ SMA cells still were observed in the smooth muscle layer (Figure 2C); however, SMC differentiation was hindered as indicated by the reduction of calponin expression in RBPMS2 misexpressing stomachs in comparison with GFP controls (Figure 2C, Supplementary Figure 3). HuC/D-positive neurons were organized into well-defined plexuses, suggesting that RBPMS2 misexpression did not induce detectable changes in ENS migration and differentiation (Figure 2C). Finally, the SMC proliferation rate was 1.55 -fold higher in RBPMS2 misexpressing stomachs than in GFP controls (Figure 2C, Supplementary Figure 4), as indicated by the expression of phosphorylated histone 3-Ser10 (PH3), a standard marker of G2/M transition. Similarly, sustained RBPMS2 expression in the developing colon mesenchyme did not affect SMC determination, whereas it inhibited calponin expression (Supplementary Figure 5). Altogether, these results indicate that a tight regulation of RBPMS2 expression is important for the normal development and differentiation of gastrointestinal smooth muscle. In addition, we investigated the contractile function at the organ level in control and RBPMS2-overexpressing gizzards (E15) by recording the smooth muscle contraction in ex vivo organ experiments (Figure $2 D$ ). Addition of carbachol triggered 
A
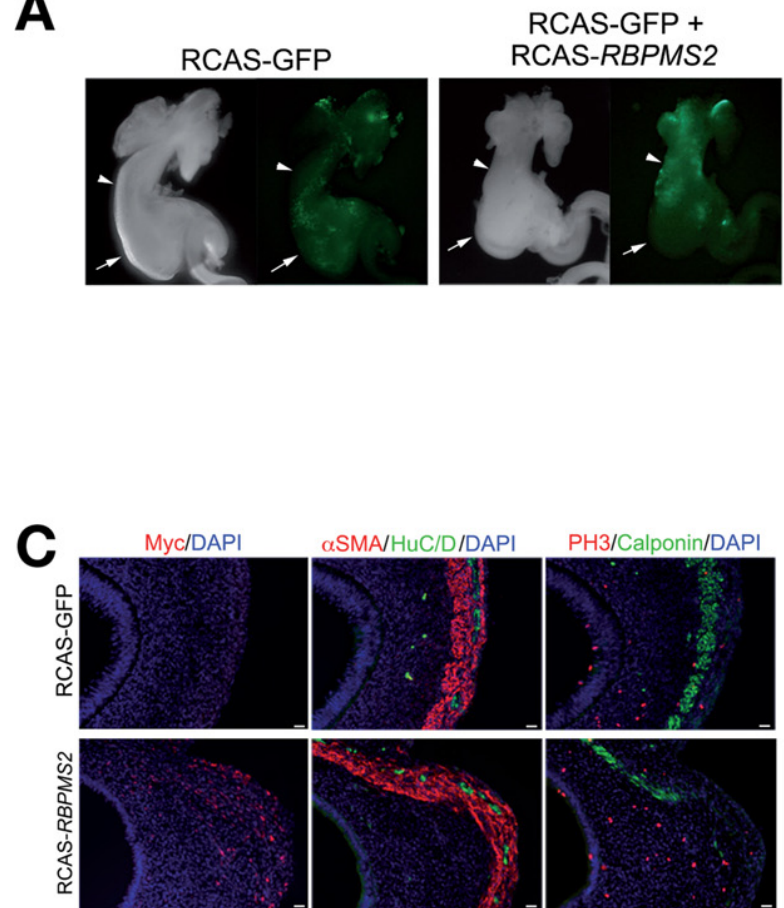

$\mathrm{PH} 3 /$ Calponin/DAPI

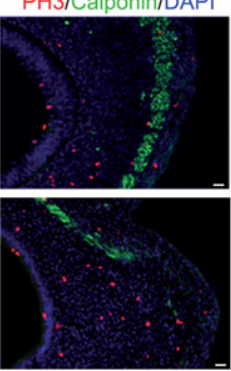

B
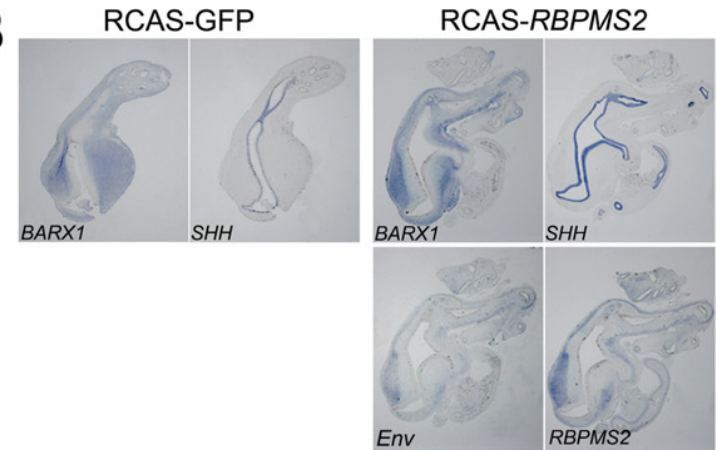

D

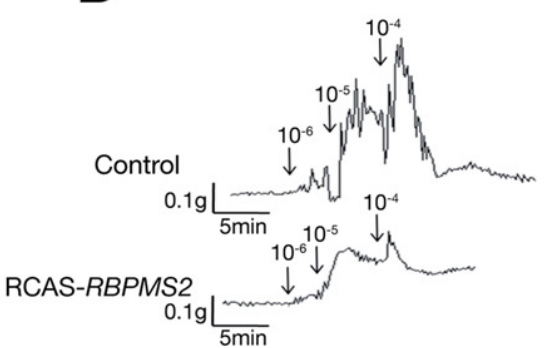

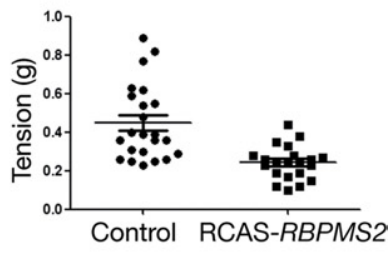

Figure 2. Sustained RBPMS2 expression alters chick gastrointestinal development, SMC differentiation, and contractile function. (A) E9 stomachs after retroviral misexpression of RCAS-GFP (as control) or both RCAS-RBPMS2 and RCAS-GFP. The presence of retroviruses is confirmed by direct observation of GFP expression. White arrows and arrowheads indicate the gizzard and the proventriculus, respectively. (B) Serial longitudinal sections of E9 stomach analyzed by in situ hybridization after RCAS-RBPMS2 misexpression using retroviral Envelop (Env), $R B P M S 2, B A R X 1$, and SHH riboprobes. Control E9 stomachs were analyzed with BARX1 and SHH riboprobes. (C) Serial transversal sections of E9 stomachs infected with RCAS-GFP or RCAS-RBPMS2 retroviruses and analyzed by immunofluorescence. Nuclei visualized with Hoechst. Antibodies against SMC ( $\alpha$ SMA and calponin), neuronal (HuC/D), and mitotic (PH3) markers were used. Anti-Myc antibodies were used to identify cells infected by RCAS-RBPMS2 retroviruses. Scale bar, $20 \mu \mathrm{m}$. (D) Measurement of contractile activity in isolated E15 gizzards. Typical recording showing stimulation with $10^{-6}$ to $10^{-4} \mathrm{~mol} / \mathrm{L}$ carbachol in normal and RBPMS2-overexpressing organs (left panels). Maximum tension after 2 minutes of $10^{-4} \mathrm{~mol} / \mathrm{L}$ carbachol stimulation in normal $(\mathrm{n}=23)$ and RBPMS2-overexpressing $(\mathrm{n}=21)$ gizzards $($ right pane/). Values are the mean \pm standard error of the mean.

the contraction of gizzard muscles in a dose-dependent manner with a maximal tension reached at $10^{-4} \mathrm{~mol} / \mathrm{L}$. The contraction was weaker in gizzards overexpressing RBPMS2 $(0.24 \pm 0.02 \mathrm{~g} ; \mathrm{n}=21)$ than in control gizzards $(0.45 \pm 0.04 \mathrm{~g} ; \mathrm{n}=23 ; P<.001)$.

To determine how RBPMS2 regulates visceral SMC differentiation, we established primary cultures on Matrigel of visceral differentiated SMCs from E15 gizzard muscles in serum-free medium supplemented with insulin. In this condition, cultured differentiated SMCs can display phenotypic modulation upon exogenous stimulation. ${ }^{18,19}$ Control primary cultured SMCs were spindle-shaped and homogenously expressed $\alpha$ SMA and calponin, 2 SMC contractile markers, in highly organized filament bundles (Figure $3 A$ ). SMCs then were infected with replication-competent retroviruses (RCAS-RBPMS2 construct or RCAS-empty [control]) for 3 days. Although in control cells the expression of $\alpha$ SMA and calponin remained unchanged (Figure $3 A$, Supplementary Figure 6), in SMCs infected with Myc-tagged RBPMS2 their expression was lost (Figure 3A, Supplementary Figure 7). However, Myc-positive cells still expressed the mesenchymal marker Desmin (Figure 3A), confirming that they were mesenchymal-derived cells. Quantitative reverse-transcription polymerase chain reaction (QPCR) using RNA from cells infected with RCAS-RBPMS2 or RCAS-empty for 3 days confirmed the down-regulation of calponin, $\alpha S M A$, and SM22 expression (Figure 3B). Analysis of the effect of RBPMS2 overexpression on serum response factor $(S R F)$ and its co-activator Myocardin, which control numerous steps of SMC differentiation, ${ }^{20}$ indicated that Myocardin mRNA was upregulated (2-fold), whereas $S R F$ expression was not significantly affected (Figure $3 B$ ). Similarly, four and a half LIM domains 2 (FHL2) mRNA, which inhibits the induction of smooth muscle contractile genes regulated by SRF, ${ }^{21}$ was up-regulated (Figure 3B, Supplementary Figure 8). To analyze the impact of ectopic RBPMS2 expression on Myocardin protein level, we co-transfected primary cultured SMCs with a plasmid-encoding myocardin and either RBPMS2 or empty (control) retroviral constructs. In SMCs overexpressing $R B$ $P M S 2$, the myocardin protein level was increased in comparison with control (Supplementary Figure 9). Because myocardin accumulates in response to proteasome inhibition by MG132,22 we transfected primary cultured SMCs with a plasmid encoding for myocardin with or without $5 \mu \mathrm{mol} / \mathrm{L}$ MG132. Ectopic myocardin expression increased calponin expression (Supplementary Figure 9). Moreover, in accordance with published work, ${ }^{22}$ proteasome inhibition by MG132 induced accumulation of myocardin, but reduced 

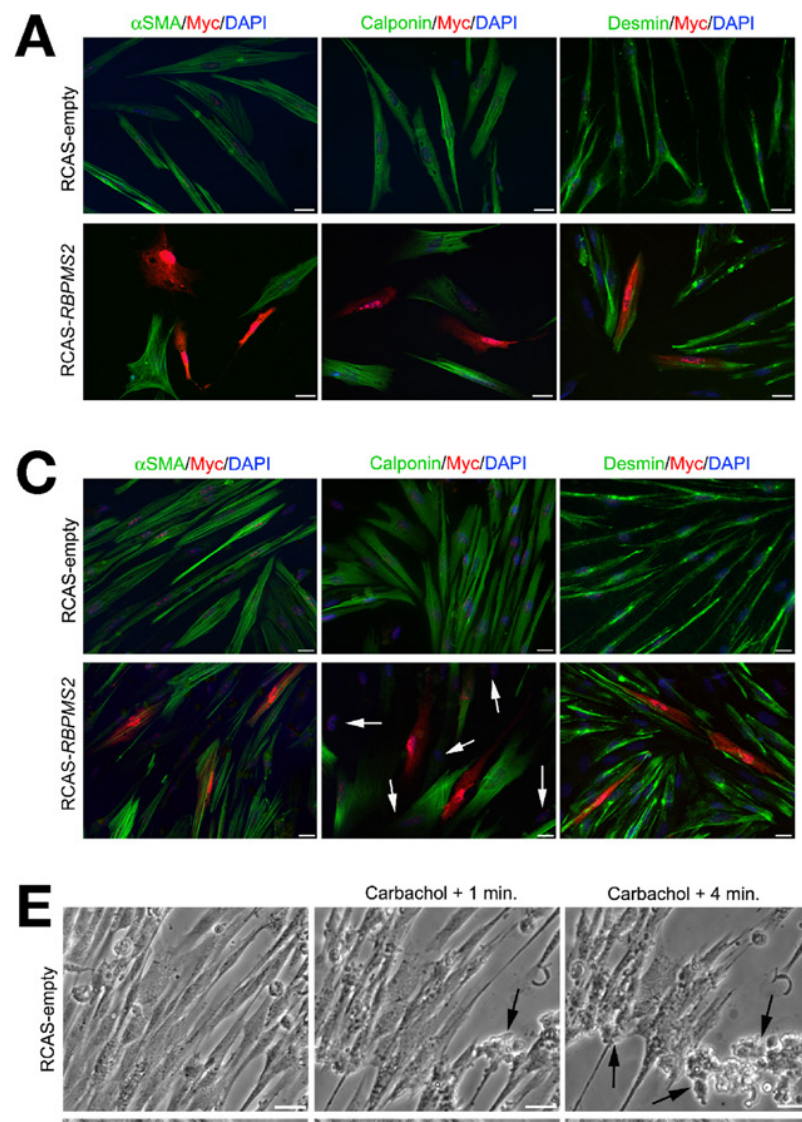

\section{Carbachol $+1 \mathrm{~min}$.}

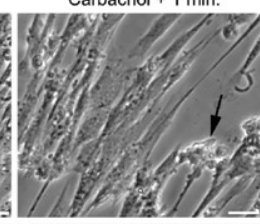

Carbachol + $4 \mathrm{~min}$
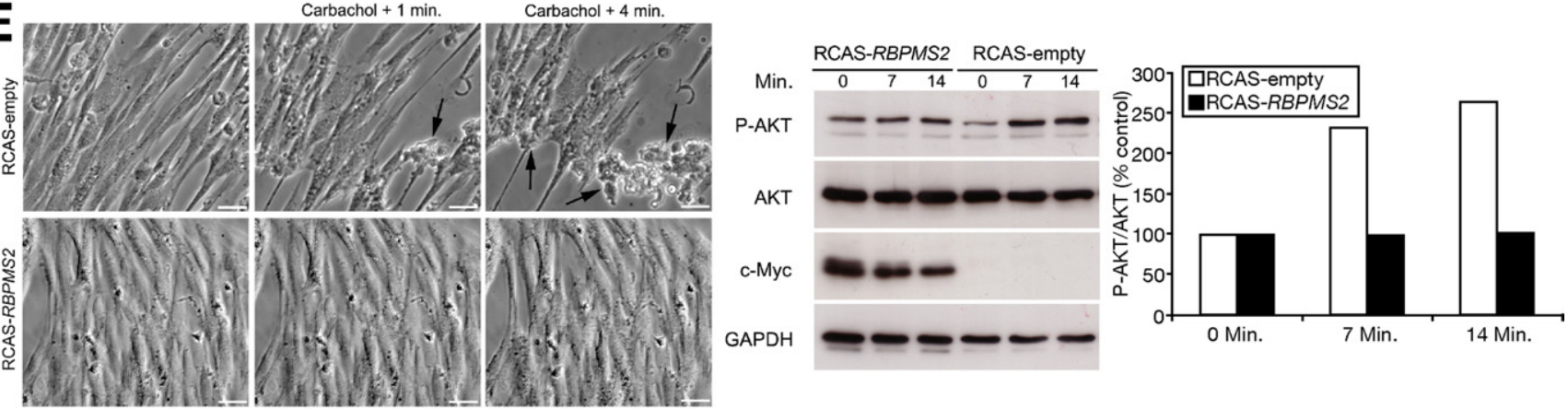

Figure 3. RBPMS2 overexpression hinders SMC differentiation and ability to contract. Immunofluorescence analysis of primary cultured SMCs infected with RCAS-empty or RCAS-RBPMS2 retroviruses for $(A) 3$ and $(C) 7$ days. Nuclei were visualized with Hoechst. Antibodies against SMC ( $\alpha$ SMA and calponin) and mesenchymal cell (desmin) markers were used. Anti-Myc antibodies were used to identify cells infected by RCAS-RBPMS2 retroviruses. Scale bar, $20 \mu \mathrm{m}$. White arrows indicate Myc-negative cells with loss of calponin expression. (B) Gene expression analysis by QPCR in primary cultured SMCs infected with RCAS-empty or RCAS-RBPMS2 retroviruses for 3 days. Normalized expression levels were converted to fold changes \pm standard deviation (RCAS-RBPMS2 vs RCAS-empty). ${ }^{\star \star} P<.01 ;{ }^{* \star} P<.001$. (D) Quantification of mitotic cells using anti-PH3 antibodies in primary cultured SMCs infected with RCAS-empty or RCAS-RBPMS2 retroviruses for 7 days. Values are the mean \pm standard error of the mean of 2 independent experiments. ${ }^{\star \star} P<.01$. (E) Contractility assays in primary cultured SMCs infected with RCAS-empty or RCAS-RBPMS2 retroviruses for 7 days and then stimulated with $10^{-3} \mathrm{~mol} / \mathrm{L}$ carbachol (left panels). Images were acquired before and at 1 minute and 4 minutes after carbachol addition. Arrows show contracted cells in control cultures. Scale bar, $40 \mu \mathrm{m}$. Immunoblot analysis of phosphorylated P-AKT (62 kilodaltons) and total AKT (62 kilodaltons) in primary cultured SMCs infected with RCAS-empty or RCAS-RBPMS2 for 7 days and treated with $10^{-4} \mathrm{~mol} / \mathrm{L}$ carbachol for 7 and 14 minutes (middle panel). Anti-Myc antibodies detected the expression of Myc-tagged RBPMS2 (26 kilodaltons). Loading was verified by glyceraldehyde-3-phosphate dehydrogenase (GAPDH) expression (37 kilodaltons). Right panel shows the quantification of the Western blot data.

calponin expression (Supplementary Figure 9). Altogether, these findings indicate that ectopic RBPMS2 expression in visceral SMCs induces accumulation of myocardin, which is critical for its function. After 7 days, $\alpha$ SMA expression was recovered in RBPMS2-overexpressing SMCs, whereas loss of calponin expression spread to adjacent nontransfected (Mycnegative) cells (Figure 3C, white arrows). As before, RBPMS2overexpressing cells were desmin-positive (Figure $3 C$ ). Moreover, the number of $\mathrm{PH} 3$-positive cells was 6-fold higher in cells that overexpressed RBPMS2 than in controls (Figure $3 D)$, suggesting a global change in the proliferative status of SMCs upon RBPMS2 deregulated expression.
To investigate the effects of RBPMS2 overexpression on visceral SMC contractility, primary cultured SMCs were stimulated with carbachol. Many control cells (RCAS-empty) became round and detached from the disc surface, showing their effective capacity to contract (Figure $3 E$ ). Conversely, RBPMS2-overexpressing SMCs were more broad-shaped than control cells and, after addition of carbachol, only few became round and detached from the disc surface (Figure $3 E$ ). Recently, intestinal SMC dedifferentiation and inability to contract upon carbachol stimulation were correlated with decreased expression of cholinergic receptor muscarinic $3 \mathrm{mRNA}$ and of carbachol-induced phosphorylated AKT (P-AKT). ${ }^{23}$ 
A

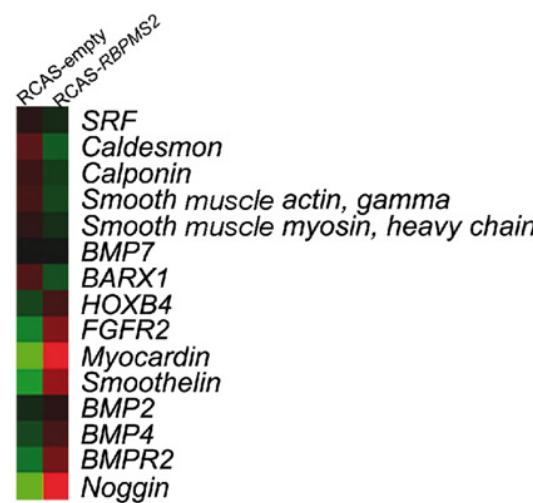

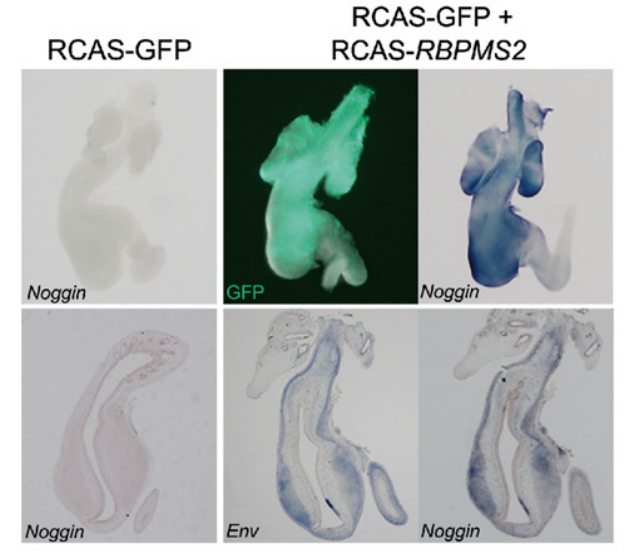

B

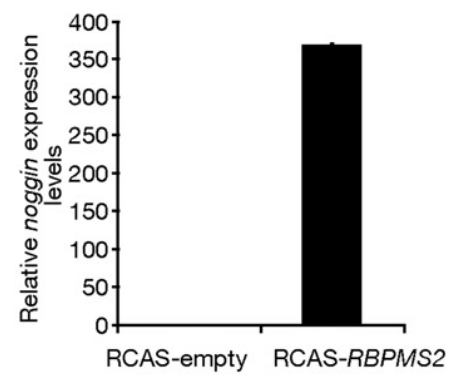

D

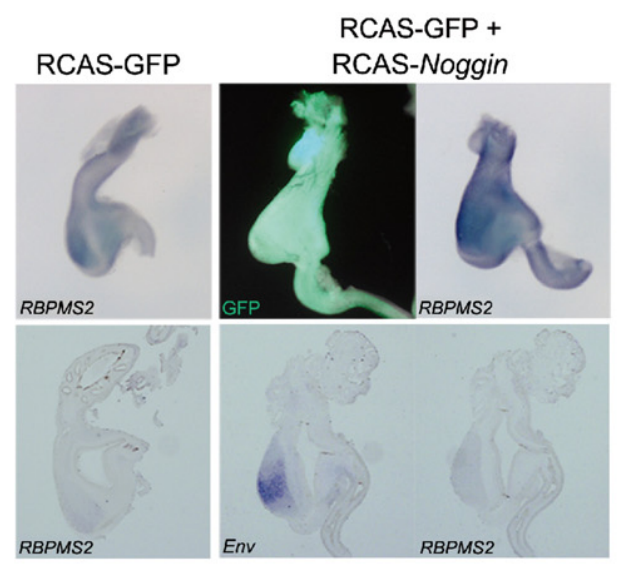

$\mathbf{E}$

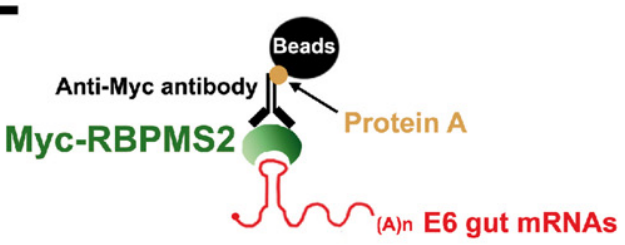



F RCAS-empty RCAS-RBPMS2

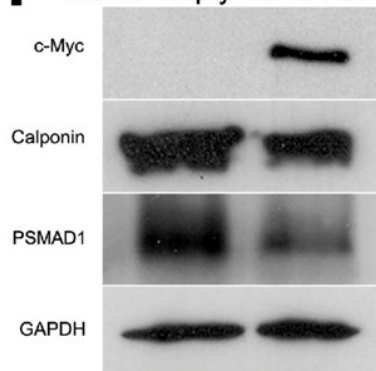

Figure 4. RBPMS2 inhibits BMP signaling through Noggin up-regulation. (A) Identification of RBPMS2 target genes by microarray using RNA from primary cultured SMCs infected with RCAS-empty or RCAS-RBPMS2 for 3 days. Highest signals are in red, and lowest signals are in green. (B) Analysis of Noggin expression by QPCR in primary cultured SMCs infected with RCAS-empty or RCAS-RBPMS2 retroviruses for 3 days. Data were normalized to ubiquitin expression and shown as mean \pm standard deviation. In situ hybridization analysis in whole-mount (upper panels) and serial longitudinal sections (lower panels) of E7 stomachs infected with RCAS-GFP (control), or (C) RCAS-GFP and RCAS-RBPMS2 or (D) RCAS-Noggin retroviruses. Infection was confirmed by observation of GFP expression or detection of Env expression. (E) Immunoprecipitation assays to identify mRNAs that interact with RBPMS2. Schematic representation of the approach (left pane/) and QPCR to detect RBPMS2-associated mRNAs using specific primers (right panel). The mean expression levels \pm standard error of the mean of Noggin and ubiquitin were measured in each condition. $(F)$ Immunoblot analysis of PSMAD1 (55 kilodaltons) and Calponin (34 kilodaltons) expression in primary cultured SMCs infected with RCAS-empty or RCAS-RBPMS2 for 3 days. Anti-Myc antibodies detected the expression of Myc-tagged RBPMS2 (26 kilodaltons). Loading was verified by glyceraldehyde-3-phosphate dehydrogenase (GAPDH) expression (37 kilodaltons).

Similarly, we found that cholinergic receptor muscarinic 3 mRNA expression was decreased by $56 \%$ in RBPMS2-overexpressing SMCs compared with controls (Supplementary Figure 10). Moreover, addition of $10^{-4} \mathrm{~mol} / \mathrm{L}$ carbachol for 14 minutes resulted in an increase of P-AKT to $264 \%$ in control SMCs, although the total level of AKT was unchanged. Conversely, no detectable change in P-AKT level was observed in RBPMS2-overexpressing SMCs (Figure 3E). These experiments show that RBPMS2 sustained expression in dif- ferentiated SMCs hinders their ability to contract and favor their proliferation, leading to their dedifferentiation.

\section{RBPMS2 Inbibits BMP Signaling Through Induction of Noggin Expression}

To identify the underlying molecular mechanism(s) of RBPMS2 action, we analyzed the gene expression profiles of primary cultured SMCs infected with RCAS-RBPMS2 or RCASempty retroviruses for 3 days (Figure $4 A$ ) by microarray analysis. 
RBPMS2 overexpression in differentiated SMCs induced the down-regulation of calponin and also of markers of SMC differentiation, such as caldesmon and SM-MHC. Conversely, Noggin, the BMP signaling pathway inhibitor, was 360-fold up-regulated (Figure $4 A$ ), whereas BMP transcriptional targets, including PITX2, ID2, and ID4, were down-regulated, suggesting a major inhibition of BMP activity (data not shown). Noggin up-regulation was confirmed by QPCR using primary SMCs harvested after 3 days of RCAS-RBPMS2 infection (Figure $4 B$ ).

Because Noggin expression pattern has not been described in detail, ${ }^{24}$ we performed in situ hybridization and showed that Noggin was expressed in gut mesenchymal derivatives as early as RBPMS2 (Supplementary Figure 11). Moreover, because misexpression of Noggin in stomach induces a hypertrophic phenotype ${ }^{16}$ that is highly reminiscent of the defects observed upon RBPMS2 misexpression, we monitored Noggin expression by in situ hybridization after RBPMS2 misexpression in the gastrointestinal mesenchyme as before. Noggin was strongly up-regulated in stomach and lung in comparison with controls (Figure 4C). Conversely, misexpression of Noggin had a moderate impact on the spatiotemporal expression of RBPMS2 (Figure 4D). Altogether, these results show that RBPMS2 induces Noggin expression and accumulation in vivo and in primary cultured SMCs.

Because RBPMS2 can bind to RNAs via its RRM domain, we investigated whether Noggin up-regulation in primary SMCs and in vivo upon RBPMS2 misexpression could be caused by interaction between RBPMS2 and Noggin. First, Myc-tagged RBPMS2 from infected DF-1 cells was immunoprecipitated with anti-Myc antibodies bound to protein A Sepharose beads in the presence of total RNA from E6 gastrointestinal mesenchyme. QPCR showed that Noggin was strongly amplified (6\% of total Noggin mRNA) after immunoprecipitation of Myc-tagged RBPMS2 (Figure 4E, Supplementary Figure 12), indicating that Noggin mRNA and RBPMS2 are present in a common RNA-protein complex. Then, we investigated the impact of the RBPMS2/Noggin interaction on the activity of the BMP signaling pathway with antibodies against the activated and phosphorylated intracellular BMP effectors SMAD1, 5, and 8 (namely PSMAD1) that we previously characterized as tools to evaluate the activity of BMP pathway. ${ }^{10,25}$ In control primary SMCs, high expression of PSMAD1 was associated with calponin expression. In cells infected with RCAS-RBPMS2 for 3 days, calponin expression decreased concomitantly with a strong reduction of PSMAD1 expression (Figure 4F), showing an inhibitory effect of RBPMS2 on the BMP signaling pathway, but also indirectly a positive effect of RBPMS2 on Noggin mRNA transcription or stabilization.

These results show that RBPMS2 positively regulates Noggin expression, leading to inhibition of BMP activity.

\section{Noggin Downstream of RBPMS2 Alters SMC Differentiation}

To evaluate whether Noggin is an essential relay of RBPMS2, we focused on Noggin function during visceral
SMC development and differentiation. We thus misexpressed Noggin in stomach throughout visceral muscle development and analyzed the differentiation of visceral SMCs. Noggin misexpression inhibited calponin expression in comparison with GFP controls, showing an alteration of visceral SMC differentiation without significant changes of the proliferative rate in vivo (Supplementary Figure 4). Moreover, immunofluorescence analysis of primary cultured SMCs after 3 days of infection with RCASNoggin retroviruses showed that $\alpha \mathrm{SMA}$ was expressed uniformly, whereas calponin expression was strongly decreased (Figure 5A). QPCR analysis of these cells showed that calponin and SM22 were down-regulated, whereas $\alpha S M A$, myocardin, and FHL2 were induced (Figure 5B, Supplementary Figure 8). Noggin overexpression also increased myocardin protein level (Supplementary Figure 9), as previously observed with RBPMS2 overexpression. Conversely, Noggin overexpression did not affect the proliferation rate of primary SMCs, as indicated by the absence of significant variations in the number of PH3-positive RCAS-Noggin cells in comparison with control cells (RCAS-empty) (Figure $5 C ; 7$ days of infection). These experiments show a common repressive action of RBPMS 2 and Noggin on SMC differentiation, but divergent effects on the proliferative rate of primary cultured SMCs.

Noggin inhibits BMP signaling by interfering with homodimerization or heterodimerization of BMP ligands, thus blocking their interaction with receptors and preventing their activation. ${ }^{25}$ Because our results suggest that the RBPMS2 effect on calponin expression in SMCs is mediated through inhibition of the BMP pathway via Noggin induction, we assessed the impact of RBPMS2 misexpression on SMC differentiation in the presence or absence of BMP4, the most strongly expressed BMP ligand in the gastrointestinal musculature. ${ }^{2,16,19}$ As previously observed in vascular SMC cultures, addition of BMP4 for 4 days increased differentiation of primary SMCs (data not shown). ${ }^{19}$ Addition of $20 \mathrm{ng} / \mathrm{mL}$ BMP4 to RCAS-RBPMS2-infected SMCs restored calponin expression in the uninfected neighboring cells, but not in the infected cells (Figure $5 D$, right panel, and Figure $5 E$ for quantification). Indeed, RBPMS2 overexpression in SMCs decreases calponin expression in infected (Myc-positive) and uninfected (Myc-negative) neighboring cells (Figures $3 C$ and $5 D$, left panel), suggesting that RBPMS2 acts both in an autocrine and paracrine manner. QPCR analysis confirmed that BMP4 addition to cells infected with RCASRBPMS2 restored expression of both calponin and SM22 (Figure 5F).

These experiments show that Noggin hinders SMC differentiation downstream of RBPMS2.

\section{RBPMS2 Transcripts Are Highly Expressed in Visceral Smooth Muscles of Patients With CIPO}

Intestinal motility disorders in infants comprise many heterogeneous diseases that are classified as gastrointestinal neuromuscular disorders and have clinical 


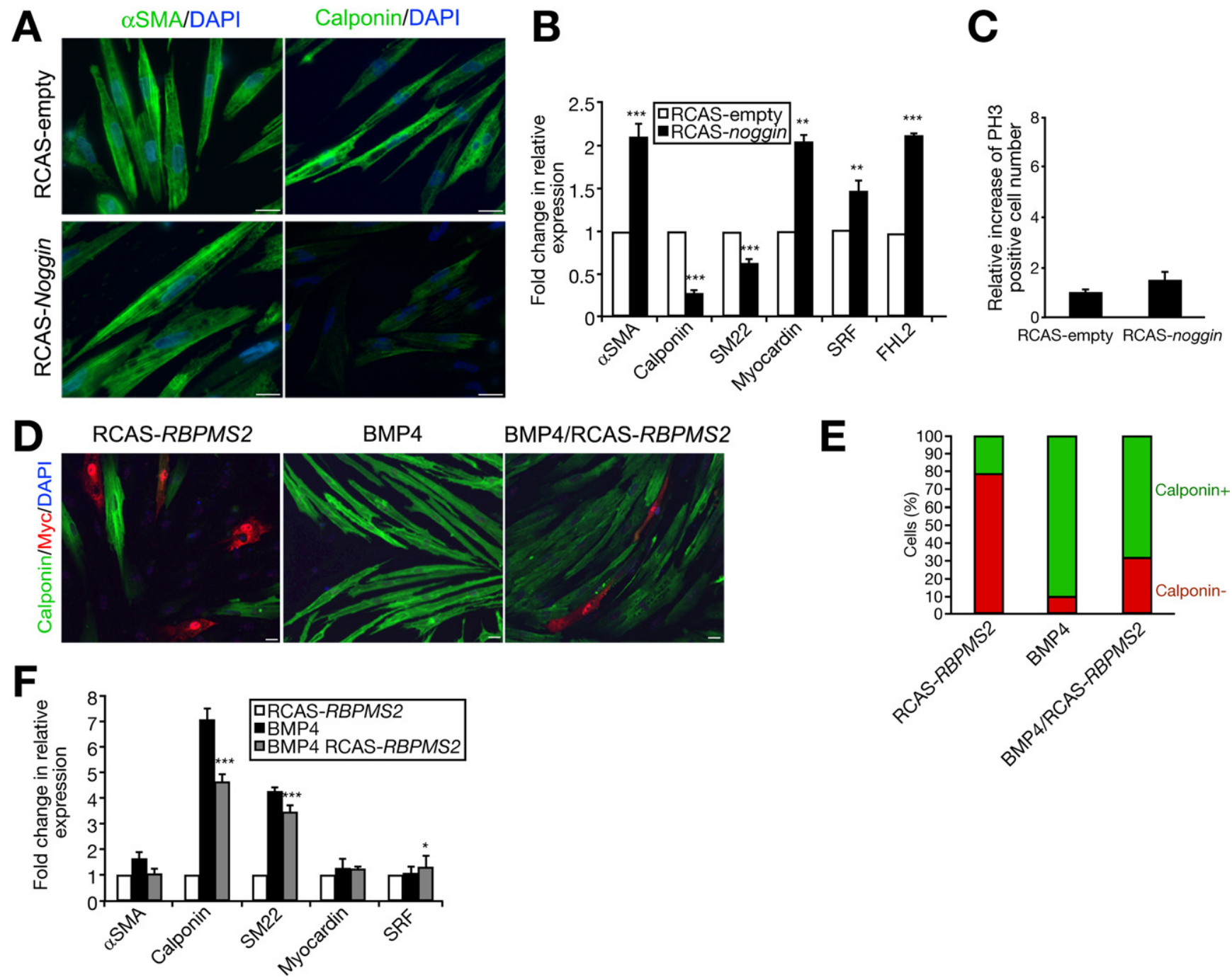

Figure 5. Noggin overexpression decreases the expression of SMC contractile proteins downstream of RBPMS2. (A) Immunofluorescence analysis of primary cultured SMCs infected with RCAS-empty or RCAS-Noggin retroviruses for 3 days. Nuclei were visualized with Hoechst. Antibodies directed against SMC markers ( $\alpha$ SMA and calponin) were used. Scale bar, $20 \mu \mathrm{m}$. (B) Analysis of gene expression by QPCR in primary cultured SMCs infected with RCAS-empty or RCAS-Noggin retroviruses for 3 days. Normalized expression levels were converted to fold changes \pm standard deviation (RCAS-Noggin vs RCAS-empty). ${ }^{\star \star} P<.01$; ${ }^{\star \star *} P<.001$. (C) Quantification of mitotic cells using anti-PH3 antibodies in primary cultured SMCs infected with RCAS-Noggin retroviruses for 7 days. Values are the mean \pm standard error of the mean of 2 independent experiments. No statistical significance. (D) Immunofluorescence analysis of primary cultured SMCs infected with RCASRBPMS2 retroviruses in the presence or not of BMP4 for 4 days. Nuclei were visualized with Hoechst. Antibodies against calponin and Myc were used. Scale bar, $20 \mu \mathrm{m}$. (E) Quantification of calponin-positive cells in the different conditions described in panel $D$. $(F)$ QPCR analysis of gene expression in primary SMCs infected with RCAS-RBPMS2 retroviruses for 7 days alone or in the presence of BMP4 in the different conditions described in panel $D$. Normalized expression levels then were converted to fold changes \pm standard deviation (treatment vs RCAS-RBPMS2). ${ }^{*} P<.05$ and ${ }^{* \star *} P<.001$ both compare with RCAS-RBPMS2.

symptoms ranging from simple constipation to intestinal occlusion..$^{4,5}$ Recently, specific smooth muscle defects were shown to be involved in the pathogenesis of pediatric digestive motility disorders. ${ }^{7}$ Because our findings suggests that RBPMS2 might be involved in visceral SMC development and differentiation, we analyzed the expression of RBPMS2 transcripts in colon biopsy specimens from pediatric patients with a history of chronic constipation associated with megacystis (CIPO), or aganglionosis (HSCR) and from neonates without digestive motility disorders (controls). Histologic analysis revealed the presence of regular circular and longitudinal smooth muscle layer in each case. Vacuolization of smooth muscles was observed in the circular smooth muscle of CIPO patients, a finding characteristic of visceral myopathy ${ }^{4}$ (Figure 6, upper panels, inset, and arrowheads). In situ hybridization showed that RBPMS2 transcripts were strongly expressed only in circular smooth muscle of colon biopsy specimens from patients with CIPO, whereas its expression was significantly lower or absent in controls and in patients with HSCR (Figure 6, lower panels). Conversely, RBPMS2 transcripts were expressed in ENS of colon sections from control neonates and patients with CIPO, 

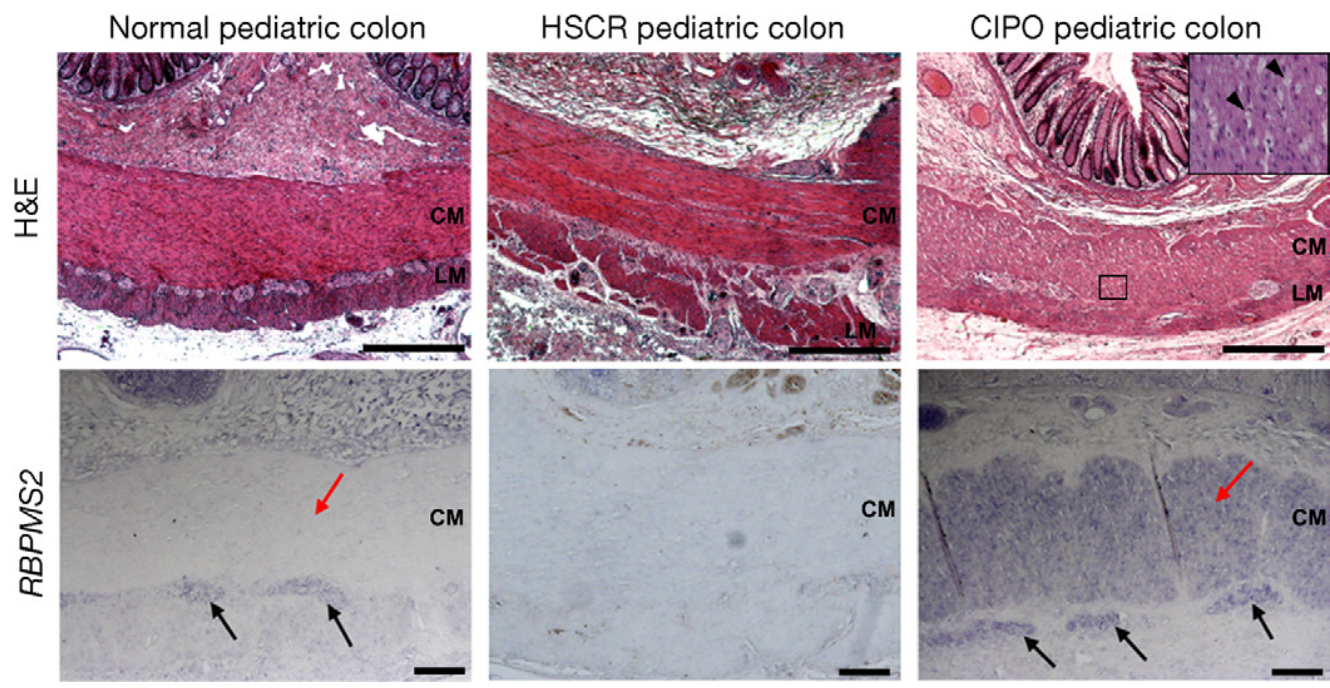

Figure 6. RBPMS2 transcript expression is abnormally high in smooth muscles from colon specimens of patients with CIPO. H\&E staining of colon sections from pediatric patients with CIPO, HSCR, and from neonates without digestive motility disorders (controls) (upper panels). The visceral musculature is composed of circular smooth muscles $(\mathrm{CM})$ and longitudinal smooth muscles $(\mathrm{LM})$. High-magnification inset of the CIPO circular muscle layer shows extensive vacuolization (arrowheads). In situ hybridization using an anti-human RBPMS2 riboprobe of consecutive sections from the same specimens (lower pane/s). Arrows and red arrows indicate staining in ganglia cells and in the circular smooth muscle layer, respectively.

but not in patients with HSCR (owing to congenital absence of ganglia) (Figure 6).

These results suggest that visceral myopathies are associated with abnormal RBPMS2 transcript expression in visceral smooth muscles.

\section{Discussion}

In this work, we investigated the expression and function of the RNA-binding protein RBPMS2 in the developing chick gastrointestinal tract. RBPMS2 expression in the chick gastrointestinal mesenchymal layer is regulated temporally because it is high at E4-E6 and then progressively is reduced at a later stage. This dynamic expression pattern corresponds to the progression of visceral undifferentiated mesenchymal cells into differentiated SMCs. Only few genes have such a dynamic expression pattern in visceral SMC precursors. $\alpha S M A$ is expressed as early as RBPMS2, but then is maintained also in differentiating SMCs, when calponin, $S M-M H C$, and myocardin also are expressed. These data identify RBPMS2 as a marker of undifferentiated visceral SMCs.

We then show that sustained RBPMS2 expression hinders visceral SMC differentiation in vivo and in SMC primary cultures through up-regulation of Noggin expression that leads to inhibition of the BMP signaling pathway. Previous studies showed that exogenous stimulation of BMP activity could prevent dedifferentiation of vascular SMCs in cell culture, suggesting that BMP activation is essential for modulating the vascular SMC phenotype. ${ }^{19}$ Our findings confirm this observation in vivo and suggest that Noggin is a key regulator during visceral SMC development and also may be involved in the phenotypic regulation of SMCs in culture (Figure 7).

We also found differences between the action of RBPMS2 and Noggin mainly in SMC primary cultures. Indeed, RBPMS2, but not Noggin, overexpression induced SMC proliferation and transient repression of $\alpha$ SMA expression. Therefore, in addition to the Noggin-BMP axis, RBPMS2 might regulate other pathways that contribute to the dedifferentiation and increased proliferation of visceral SMCs, thus dissociating the effect on proliferation from the effect on differentiation.

We show that RBPMS2 and Noggin overexpression in differentiated SMCs hinders their differentiation associated with myocardin up-regulation. Indeed, recently, Yin et $\mathrm{al}^{22}$ reported that myocardin accumulation inhibits its

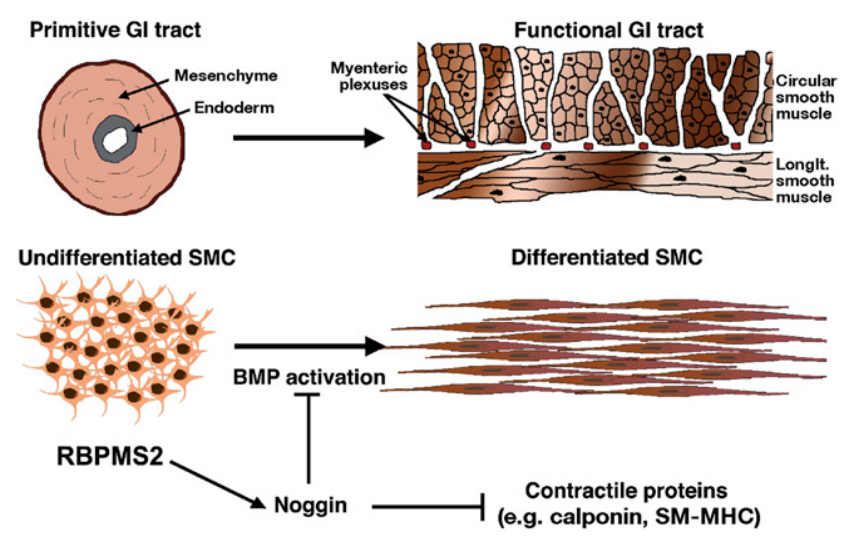

Figure 7. Model of the gastrointestinal SMC development regulated by the RBPMS2 and BMP pathways. RBPMS2 regulates the early stage of $\mathrm{SMC}$ differentiation through the control of the expression of the BMP inhibitor Noggin and the inhibition of contractile proteins. 
own function and that proteosomal degradation of myocardin is required for its full transcriptional activity. Similarly, we show that myocardin accumulation results in a reduction of calponin expression (a marker of differentiated SMCs). In addition, RBPMS2 and Noggin misexpression led to up-regulation of the SRF target gene FHL2, which interacts with SRF and inhibits induction of smooth muscle contractile genes by SRF. ${ }^{21}$ Altogether, these results support the notion that activation of the RBPMS2/Noggin pathway inhibits SMC contractile genes through functional alteration of the myocardin/SRF pathway.

In conclusion, we show that, in chick embryos, $R B$ PMS2 is expressed during the early stages of visceral SMC development and that its expression is progressively lost during differentiation of visceral smooth muscles. Ectopic expression of RBPMS2 in primary culture of differentiated SMCs triggers an increase of their proliferative rate and hinders their contractile function, which also was observed at the organ level. Our findings show that regulated expression of RBPMS 2 is important for the correct development and differentiation of visceral SMCs. We then found that RBPMS2 transcript expression was significantly higher in circular smooth muscle cells from colon specimens of pediatric patients with CIPO (digestive dysmotility syndrome in the absence of physical obstruction of the bowel), ${ }^{4-7,26}$ whereas its expression was very low or absent in specimens from patients without digestive motility disorders or with HSCR (a developmental ENS disorder). Some investigators have reported abnormal architecture of the tunica muscularis of colon specimens from patients with CIPO, suggesting a potential primary alteration of the visceral smooth muscles. ${ }^{6,7}$ In summary, we identified RBPMS2 as a new marker of visceral SMC remodeling that could be useful for the characterization of smooth muscle alteration in visceral myopathies. Future studies are needed to investigate the potential function of RBPMS2 in CIPO etiopathogenesis, particularly the alteration in the tunica muscularis.

\section{Supplementary Material}

Note: To access the supplementary material accompanying this article, visit the online version of

\section{References}

1. Sanders KM, Koh SD, Ward SM. Interstitial cells of Cajal as pacemakers in the gastrointestinal tract. Annu Rev Physiol 2006; 68:307-343.

2. de Santa Barbara P, van den Brink GR, Roberts DJ. Molecular etiology of gut malformations and diseases. Am J Med Genet 2002;115:221-230.

3. Wallace AS, Burns AJ. Development of the enteric nervous system, smooth muscle and interstitial cells of Cajal in the human gastrointestinal tract. Cell Tissue Res 2005;319:367-382.

4. Knowles CH, De Giorgio R, Kapur RP, et al. Gastrointestinal neuromuscular pathology: guidelines for histological techniques and reporting on behalf of the Gastro 2009 International Working Group. Acta Neuropathol 2009;118:271-301.
5. Knowles CH, De Giorgio R, Kapur RP, et al. The London Classification of gastrointestinal neuromuscular pathology: report on behalf of the Gastro 2009 International Working Group. Gut 2010; 59:882-887.

6. Antonucci A, Fronzoni L, Cogliandro L, et al. Chronic intestinal pseudo-obstruction. World J Gastroenterol 2008;14:2953-2961.

7. Wedel T, Van Eys GJ, Waltregny D, et al. Novel smooth muscle markers reveal abnormalities of the intestinal musculature in severe colorectal motility disorders. Neurogastroenterol Motil 2006;18:526-538.

8. Gabella G. Development of visceral smooth muscle. Results Probl Cell Differ 2002;38:1-37.

9. Mao J, Kim BM, Rajurkar M, et al. Hedgehog signaling controls mesenchymal growth in the developing mammalian digestive tract. Development 2010;137:1721-1729.

10. de Santa Barbara P, Williams J, Goldstein AM, et al. Bone morphogenetic protein signaling pathway plays multiple roles during gastrointestinal tract development. Dev Dyn 2005;234:312-322.

11. Le Guen L, Notarnicola C, de Santa Barbara P. Intermuscular tendons are essential for the development of vertebrate stomach. Development 2009;136:791-801.

12. St Johnston D. Moving messages: the intracellular localization of mRNAs. Nat Rev Mol Cell Biol 2005;6:363-375.

13. Gerber WV, Yatskievych TA, Antin PB, et al. The RNA-binding protein gene, hermes, is expressed at high levels in the developing heart. Mech Dev 1999;80:77-86.

14. Xin M, Small EM, Sutherland LB, et al. MicroRNAs miR-143 and miR-145 modulate cytoskeletal dynamics and responsiveness of smooth muscle cells to injury. Genes Dev 2009;23:2166-2178.

15. Wilmore HP, McClive PJ, Smith CA, et al. Expression profile of the RNA-binding protein gene hermes during chicken embryonic development. Dev Dyn 2005;233:1045-1051.

16. Moniot B, Biau S, Faure S, et al. SOX9 specifies the pyloric sphincter epithelium through mesenchymal-epithelial signals. Development 2004;131:3795-3804.

17. Rouleau C, Matecki S, Kalfa N, et al. Activation of MAP kinase (ERK1/2) in human neonatal colonic enteric nervous system. Neurogastroenterol Motil 2009;21:207-214.

18. Hayashi K, Saga H, Chimori Y, et al. Differentiated phenotype of smooth muscle cells depends on signaling pathways through insulin-like growth factors and phosphatidylinositol 3-kinase. J Biol Chem 1998;273:28860-28867.

19. Lagna G, Ku MM, Nguyen PH, et al. Control of phenotypic plasticity of smooth muscle cells by bone morphogenetic protein signaling through the myocardin-related transcription factors. J Biol Chem 2007;282:37244-37255.

20. Mericskay M, Blanc J, Tritsch E, et al. Inducible mouse model of chronic intestinal pseudo-obstruction by smooth muscle-specific inactivation of the SRF gene. Gastroenterology 2007;133:1960-1970.

21. Philippar U, Schratt G, Dieterich $C$, et al. The SRF target gene Fhl2 antagonizes RhoA/MAL-dependent activation of SRF. Mol Cell 2004;16:867-880.

22. Yin $\mathrm{H}$, Jiang $\mathrm{Y}$, Li $\mathrm{H}$, et al. Proteasomal degradation of myocardin is required for its transcriptional activity in vascular smooth mus cle cells. J Cell Physiol 2011;226:1897-1906.

23. Nair DG, Han TY, Lourenssen, et al. Proliferation modulates intestinal smooth muscle phenotype in vitro and in colitis in vivo. Am J Physiol Gastrointestinal Liver Physiol 2011;300:903-913.

24. Goldstein AM, Brewer KC, Doyle AM, et al. BMP signaling is necessary for neural crest cell migration and ganglion formation in the enteric nervous system. Mech Dev 2005;122:821-833.

25. Faure S, de Santa Barbara P, Roberts DJ, et al. Endogenous patterns of BMP signaling during early chick development. Dev Biol 2002;244:44-65.

26. Puig I, Champeval D, De Santa Barbara P, et al. Deletion of Pten in the mouse enteric nervous system induces ganglioneuromatosis and mimics intestinal pseudoobstruction. J Clin Invest 2009;119:3586-3596. 


\section{Reprint requests}

Address requests for reprints to: Pascal De Santa Barbara, PhD, INSERM U1046, Université Montpellier 1, Université Montpellier 2,

Montpellier, France. e-mail: pascal.de-santa-barbara@inserm.fr; fax: (33) 467-415-231

\section{Acknowledgments}

The authors thank members of INSERM U1046 for support; 0. Cazorla for smooth muscle cell contractility; A. Abdellaoui for statistical analyses;
D. J. Roberts for reagents and inspiration; J. M. Vanderwinden for helpful discussions; and N. Dulin and E. Olson for myocardin construct.

\section{Conflicts of interest}

The authors disclose no conflicts.

\section{Funding}

Research was supported by the Agence Nationale pour la Recherche (ANR-07-JCJC-0112), Association Française contre les Myopathies (AFM), French Association des Patients POIC, Région Languedoc-Roussillon (Chercheur d'Avenir) (P.D.S.B.), and C.N. is an AFM fellow. 


\section{Supplementary Materials and Methods \\ Western Blotting}

For protein immunoblotting, protein extracts $(10$ $\mu \mathrm{g}$ ) were separated on $10 \%$ polyacrylamide gels (Bio-Rad Laboratories, France) and then blotted on nitrocellulose membranes. Membranes were incubated with primary antibodies (anti-Myc from Ozyme [Montigny-Le-Bretonneux, France], anti-avian calponin from Sigma-Aldrich, anti-phosphoSMAD1 from Cell Signaling [Danvers, MA], anti-myocardin from Santa Cruz Biotechnology [Santa Cruz, CA], anti-glyceraldehyde-3-phosphate dehydrogenase from Sigma-Aldrich, and anti-total AKT and antiP-AKT from Cell Signaling) overnight and then with the relevant horseradish peroxidase-conjugated secondary antibodies. Detection was performed by chemiluminescence on Kodak films. Glyceraldehyde-3-phosphate dehydrogenase expression was used to confirm equal loading.

\section{In Situ Hybridization and Immunodetection}

Immunofluorescence and immunohistochemistry experiments with chick and human paraffin-embedded sections were performed as described. ${ }^{11,17}$ For immunodetection, anti- $\alpha$ SMA (Sigma-Aldrich), anti-Myc (Ozyme), antiavian calponin (Sigma-Aldrich), anti-HuC/D (Invitrogen, France), anti-desmin (Euromedex, Mundolsheim Cedex, France), and anti-phospho-histone H3-Ser10 (Millipore, Molsheim, France) antibodies were used. Nuclei were stained with Hoechst (Invitrogen). H\&E staining was performed using standard procedures. In situ hybridization experiments using dissected gut or paraffin sections were performed as described. ${ }^{11,16}$ Anti-sense riboprobes were generated by PCR amplification using specific primer sets and subcloned. The following chick templates were used: $\alpha S M A, E n v, R B P M S 2, B A R X 1, S H H$, and Noggin. ${ }^{24}$ Human RBPMS2 complementary DNA was isolated, sequenced, and used to prepare riboprobes for in situ hybridization. Images were acquired using a NikonAZ100 stereomicroscope and a Carl-Zeiss AxioImager microscope.

\section{Microarray Experiments and QPCR}

Total RNAs were extracted from SMC primary cultures with the HighPure RNA Isolation kit (Roche Diagnostic, France) and reverse transcription was performed as described. ${ }^{11}$ For microarray experiments, resulting complementary DNAs were biotinylated and hybridized to Affymetrix GeneChip Chicken Genome Arrays (Santa Clara, CA) following the manufacturer's protocols (IRB, CHRU Montpellier, France). ${ }^{11}$ For QPCR, gene expression levels were measured using LightCycler technology (Roche Diagnostics). PCR primers (Supplementary Table 1) were designed using the LightCycler Probe Design software 2.0. Each sample was assayed from 3 independent experiments performed in triplicate. Expression levels were determined with the LightCycler analysis software (version 3.5) relative to standard curves. Data were represented as the mean level of gene expression relative to the expression of the reference gene ubiquitin. Data were analyzed using the Student $t$ test and results were considered significant when the $P$ value was less than $.05(*), P<.01(* *)$, or $P<.001(* *)$ in Figures 3 and 5 and Supplemental Figures 4, 8, and 10. 
A

RCAS-empty

RCAS-RBPMS2
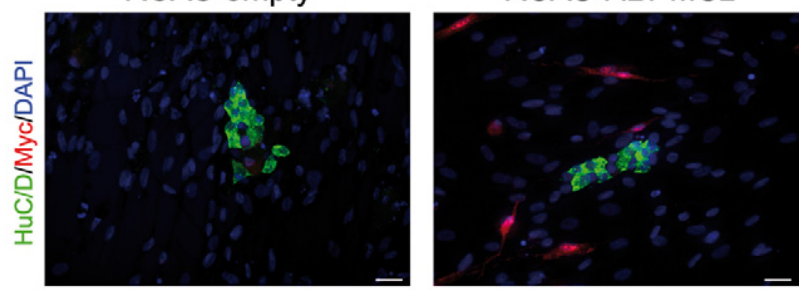

B

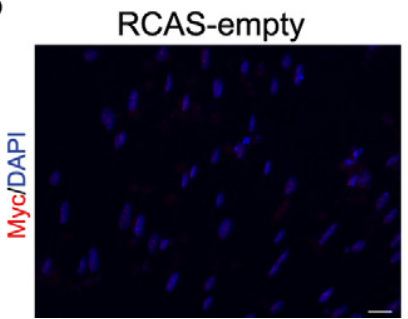

RCAS-RBPMS2

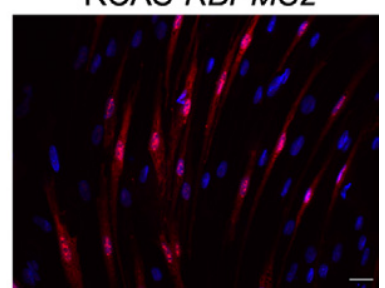

Supplementary Figure 1. Efficiency and trophism of avian retroviruses on differentiated SMC primary cultures. (A) Enteric neurons are not targeted by the retroviral misexpression system used in this study. Immunofluorescence analysis of SMC primary cultures prepared from E15 gizzard muscles infected with Myc-tagged RBPMS2 (RCAS-RBPMS2) or RCAS-empty retroviruses for 3 days. RBPMS2 retroviruses targeted exclusively visceral SMCs as indicated by Myc expression. Ectopic RBPMS2 expression had no indirect effect on the formation of the enteric plexus and on neuron differentiation as observed using anti-HuC/D antibodies. Scale bar, $20 \mu \mathrm{m}$. (B) Immunofluorescence analysis of primary cultured SMCs infected with high titers of RCASRBPMS2 or RCAS-empty retroviruses for 3 days. Nuclei were visualized with Hoechst. Anti-Myc antibodies were used to identify cells infected by RCAS-RBPMS2 retroviruses. Scale bar, $20 \mu \mathrm{m}$.
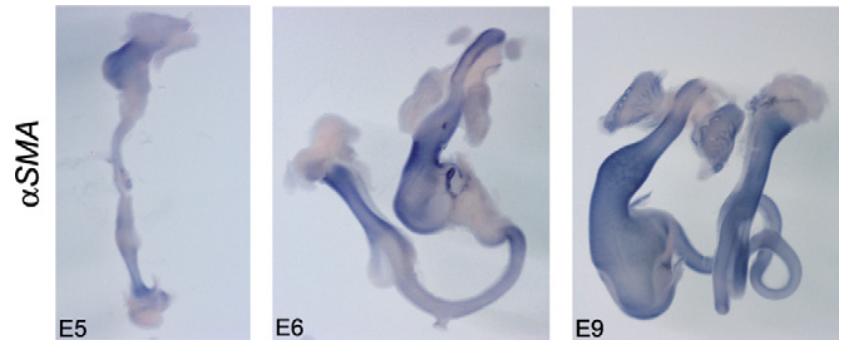

Supplementary Figure 2. $\alpha S M A$ expression in the chick gastrointestinal system. Whole-mount in situ hybridization of dissected E5, E6, and E9 chick gastrointestinal tracts using an anti-sense riboprobe directed against $\alpha S M A$. $\alpha S M A$ is expressed in the whole mesenchymal gastrointestinal tract with no difference along the anteroposterior axis in the developing and differentiated visceral smooth musculature. 

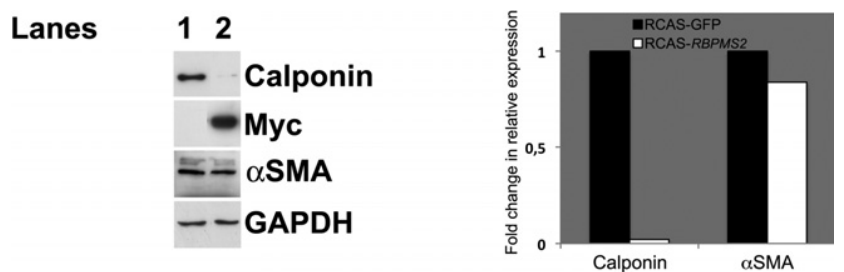

\section{E7 control (GFP) stomach}

\section{E7 RBPMS2 stomach}

Supplementary Figure 3. Sustained RBPMS2 expression strongly inhibits calponin expression. Western blot analysis of protein extracts from RCAS-Myc-RBPMS2 misexpressing stomachs (E7) compared with control organs (RCAS-GFP). A total of $10 \mu \mathrm{g}$ of whole protein extracts were processed for each condition. Chick calponin was detected with anticalponin antibodies (Sigma-Aldrich). The right panel shows the quantification of the Western blot data.

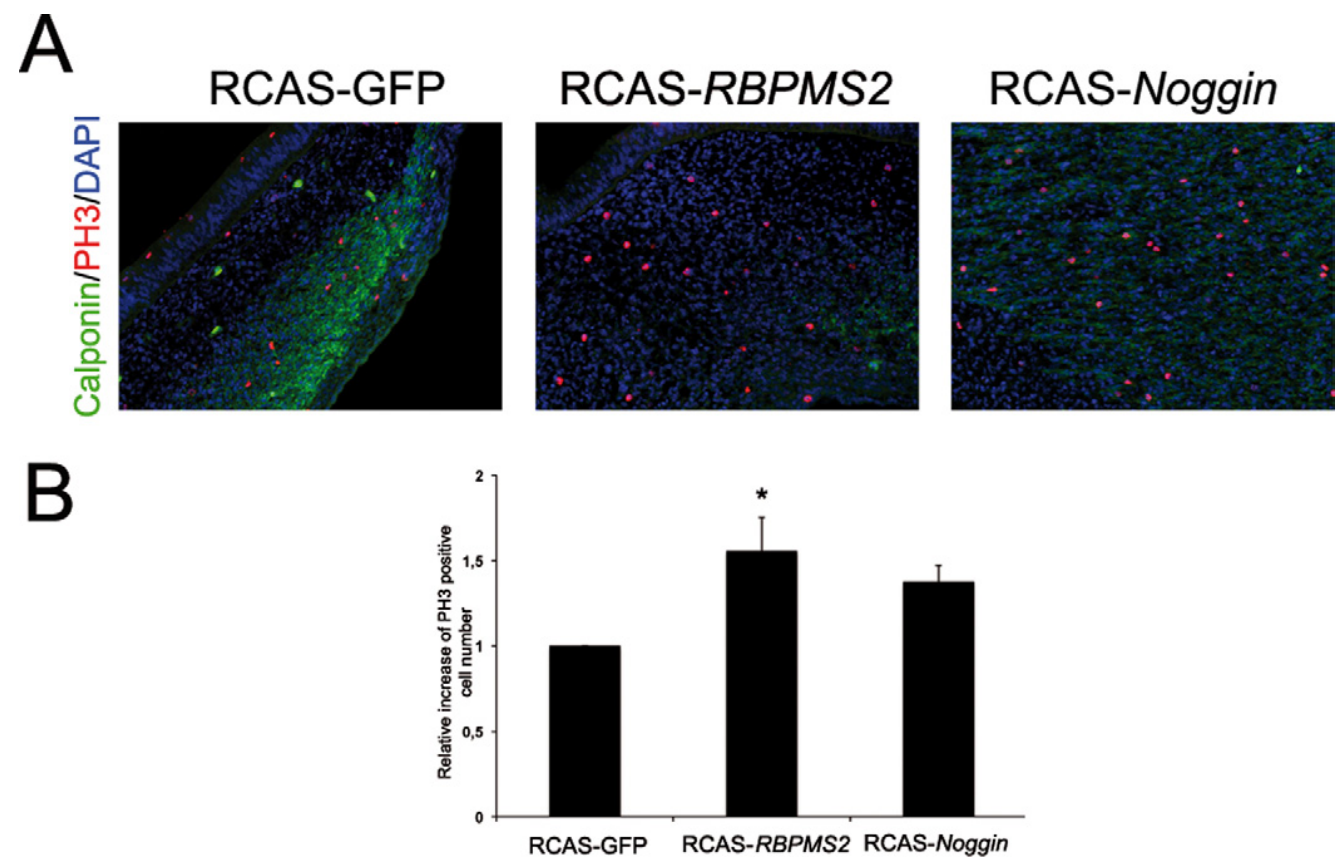

Supplementary Figure 4. Impact of RBPMS2 and Noggin sustained expression on visceral SMC differentiation and proliferation in vivo. (A) Serial transversal sections from E9 chick stomachs infected with RCAS-GFP, RCAS-RBPMS2, or RCAS-Noggin retroviruses were analyzed by immunofluorescence. Differentiated SMCs were identified with anticalponin antibodies and mitotic cells with anti-PH3 antibodies. Sustained RBPMS2 and Noggin expression inhibit calponin expression. (B) Quantification of mitotic cells using the mitotic marker PH3 in E9 chick stomachs infected with RCAS-GFP, RCAS-RBPMS2, or RCAS-Noggin retroviruses by immunofluorescence. Values are the mean \pm SEM of 3 independent experiments. Statistical analysis using the Student $t$ test confirmed the significant increase $\left(1.55\right.$-fold; $\left.{ }^{\star} P<.05\right)$ of PH3-positive cells upon $R B P M S 2$ misexpression. The 1.37-fold induction after Noggin misexpression was not statistical significant. 


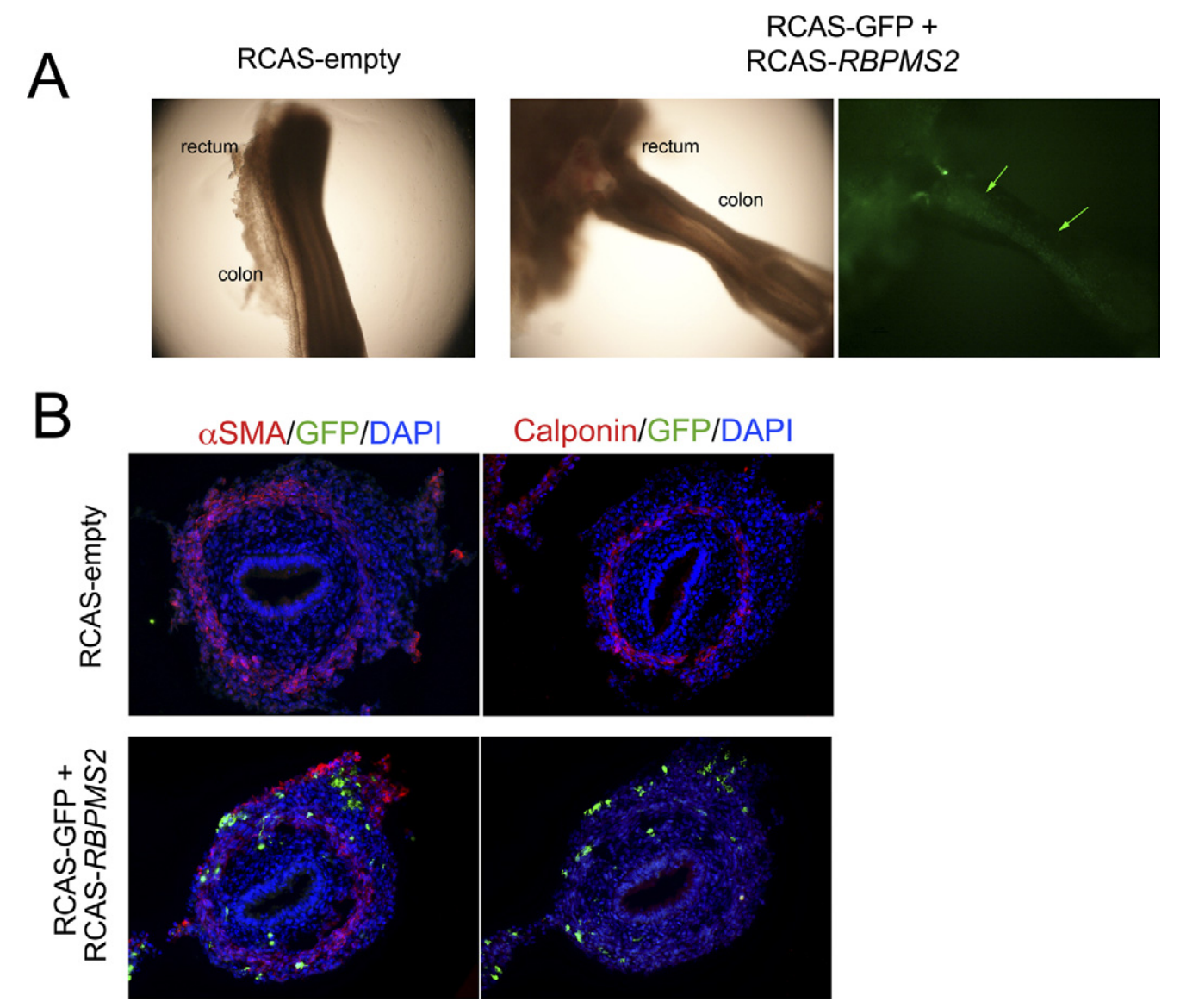

Supplementary Figure 5. Sustained RBPMS2 expression alters chick colonic SMC differentiation. (A) E7 colons after retroviral misexpression of RCAS-empty (control) (left panel) or of RCAS-RBPMS2 and RCAS-GFP (right panels). The presence of retroviruses was confirmed by direct observation of GFP expression (right panel; green arrows indicate the colon). (B) Serial cross-sections of E7 colons infected with RCAS-empty (control; upper panels) or RCAS-RBPMS2 retroviruses (lower panels) analyzed by immunofluorescence. Nuclei were visualized with Hoechst. Antibodies directed against $\alpha$ SMA and calponin were used. Anti-GFP antibodies were used to confirm infection of the colon musculature. Sustained expression of RBPMS2 specifically in the colon resulted in no morphologic alterations in comparison with controls. In addition, RBPMS2 misexpression did not affect the determination of colon SMCs because $\alpha$ SMA-positive cells still were observed in the smooth muscle layer. (B) Conversely, it inhibited calponin expression in comparison with control colons, indicating that RBPMS2 misexpression hinders SMC differentiation also in the developing colon. 

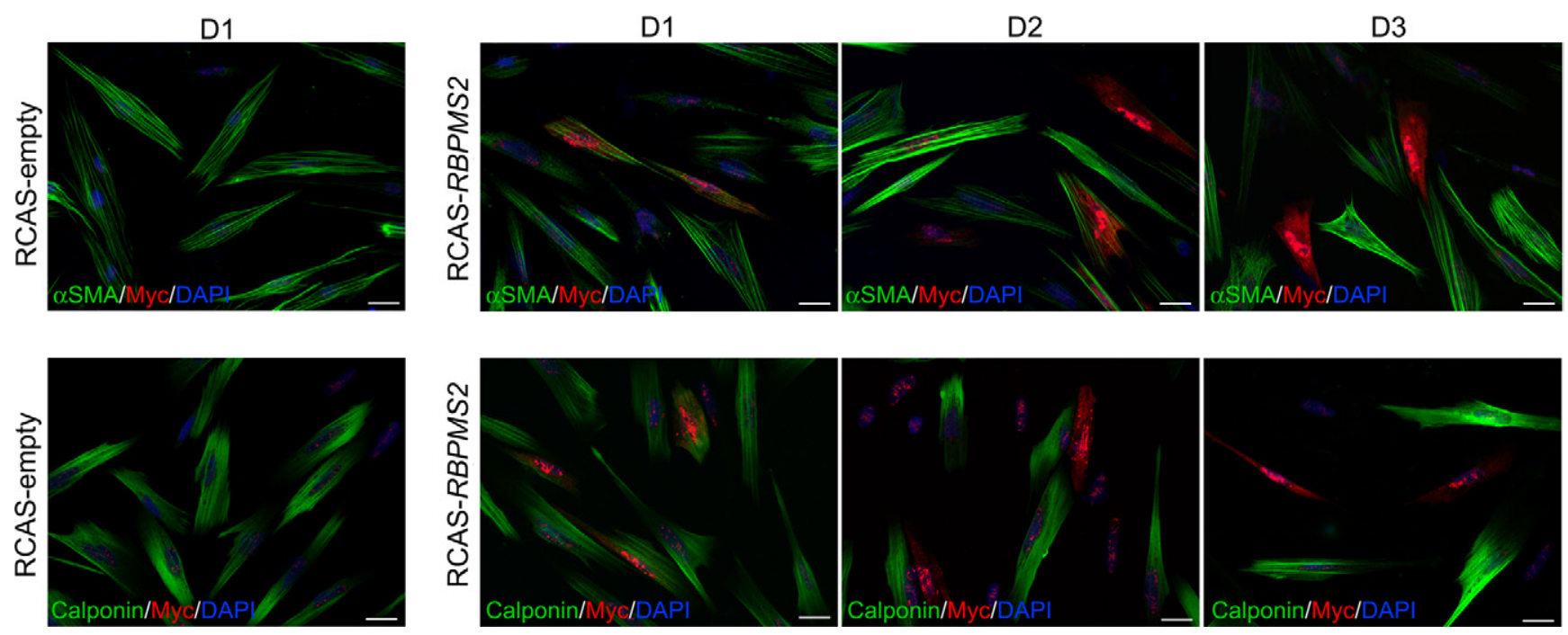

Supplementary Figure 6. Time-line study of RBPMS2 overexpression in primary cultures of differentiated SMCs. Immunofluorescence analysis of primary SMCs infected with RCAS-empty (left panels) or RCAS-RBPMS2 (right panels) retroviruses for 1 (D1), 2 (D2), and 3 (D3) days. Nuclei were visualized with Hoechst. Antibodies directed against SMC markers: $\alpha$ SMA (upper pane/s) and calponin (lower pane/s) were used. Anti-Myc antibodies were used to identify cells infected by RCAS-RBPMS2 retroviruses. RBPMS2 misexpression inhibited first the expression of calponin (after 2 days), and after 3 days $\alpha$ SMA expression also was down-regulated. Scale bar, $20 \mu \mathrm{m}$.
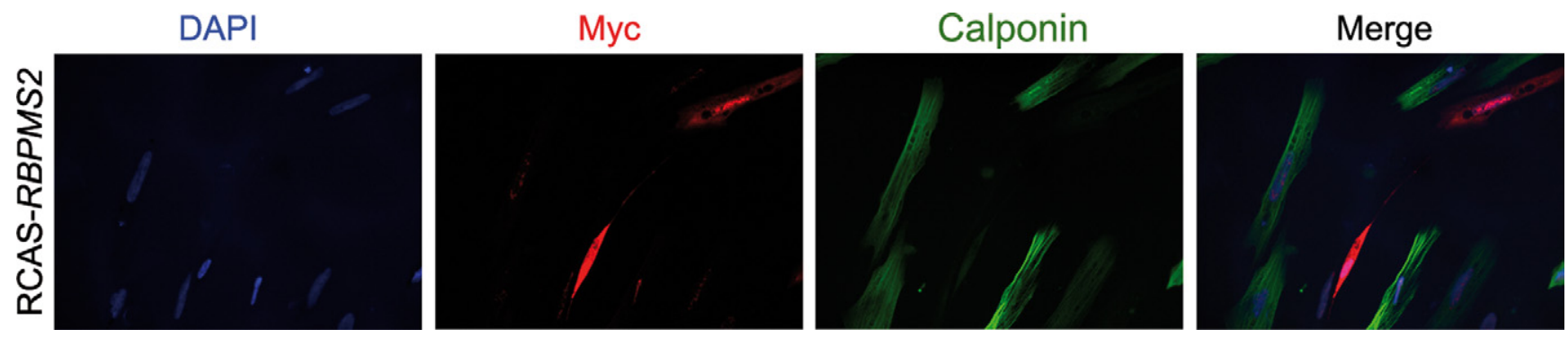

Supplementary Figure 7. Immunofluorescence analysis of SMC primary cultures prepared from E15 gizzard muscles and infected with Myctagged RBPMS2 (RCAS-RBPMS2) retroviruses for 3 days. In RBPMS2-overexpressing cells, calponin expression is inhibited. 


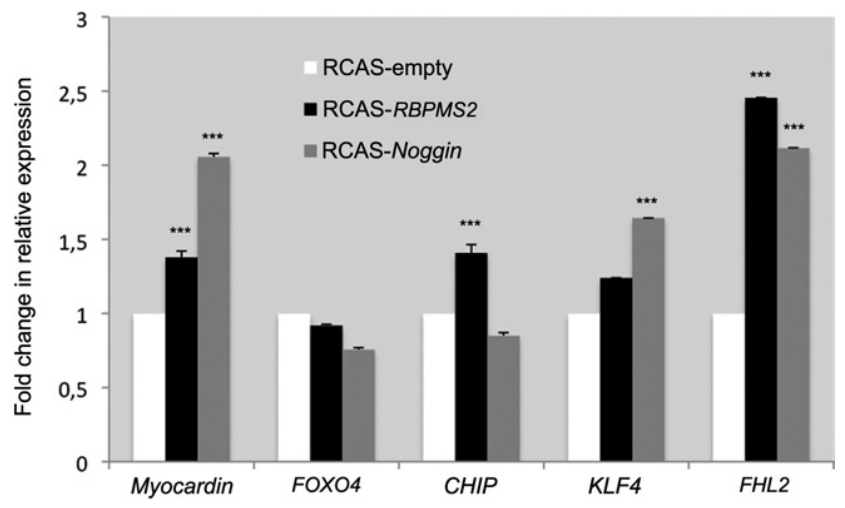

Supplementary Figure 8. Expression of mRNA levels coding for different protein partners of myocardin/SRF that modulate myocardin/SRF function during visceral SMC differentiation analyzed by QPCR in primary cultured SMCs infected with RCAS-empty, RCASRBPMS2, or RCAS-Noggin retroviruses for 7 days. Normalized expression levels were converted to fold changes \pm standard deviation (RCAS-RBPMS2 and RCAS-Noggin vs RCAS-empty). We confirmed the up-regulation of Myocardin mRNAs upon RBPMS2 and Noggin overexpression. We then found that Noggin overexpression increased Kruppel-like factor 4 (KLF4) mRNA expression by 1.5 -fold. Conversely, Noggin and RBPMS2 overexpression did not affect Forkhead box O4 (FOXO4) and C terminus of Hsc70-Interacting Protein (CHIP) expression, whereas it increased by more than 2 -fold the level of FHL2 mRNA. ${ }^{* \star *} P<.001$. 
A

\begin{tabular}{l|cccc} 
Lanes & $\mathbf{1}$ & $\mathbf{2}$ & $\mathbf{3}$ & $\mathbf{4}$ \\
\hline Myocardin & - & + & + & + \\
RCAS-empty & + & + & - & - \\
RCAS-RBPMS2 & - & - & + & - \\
RCAS-Noggin & - & - & - & +
\end{tabular}

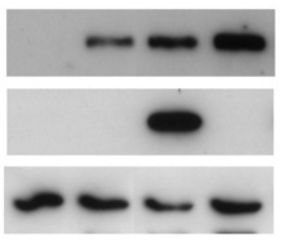

Myocardin

Myc

GAPDH
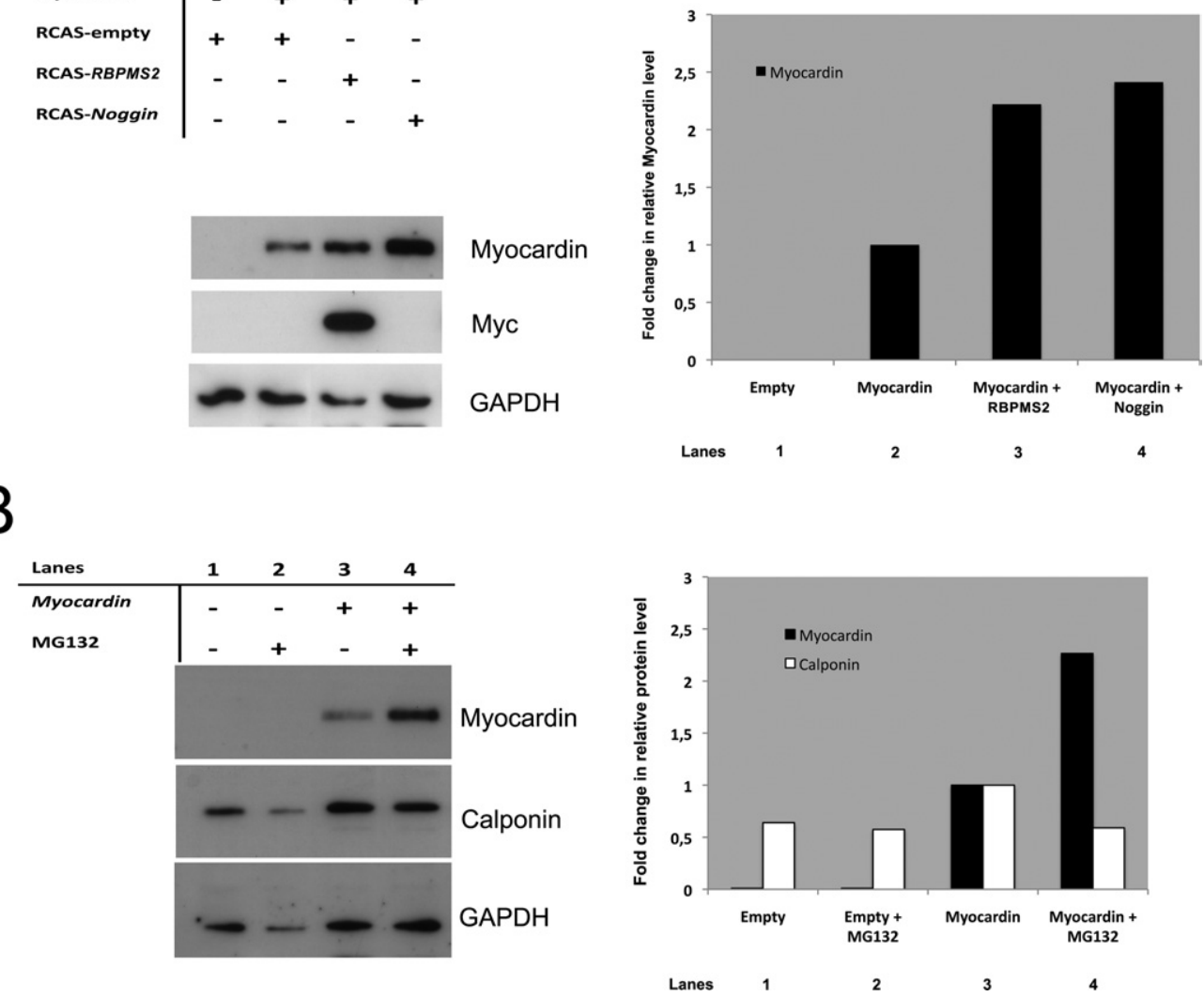

Supplementary Figure 9. Accumulation of myocardin protein in visceral SMC inhibits its function. (A) Western blot analysis of primary SMC cultures after Myocardin and RBPMS2 or Noggin ectopic expression. Primary differentiated SMCs were grown in DMEM supplemented with $10 \%$ fetal bovine serum (FBS) and cotransfected with JetPEl (Polyplus, France) with $2.5 \mu \mathrm{g}$ of a mouse myocardin construct and $2.5 \mu \mathrm{g}$ of empty or RBPMS2 or Noggin retroviral constructs and analyzed after 48 hours. A total of $15 \mu \mathrm{g}$ of whole protein extracts were processed for each condition. Myocardin (95 kilodaltons) was detected with the H300 antibody. Co-expression of Myocardin and RBPMS2 or Noggin results in accumulation of Myocardin (lanes 3 and 4). Right panel shows the quantification of the Western blot data. (B) Western blot analysis of primary SMC cultures after proteasomal inhibition with $5 \mu \mathrm{mol} / \mathrm{L}$ MG132. Primary differentiated SMCs were grown in DMEM supplemented with 10\% FBS and transfected, or not, with $5 \mu \mathrm{g}$ of a mouse myocardin construct and analyzed after 48 hours. MG132 (proteasome inhibitor) was added to the medium for 12 hours after 36 hours of transfection. A total of $15 \mu \mathrm{g}$ of whole protein extracts were processed for each condition. SMCs cultured in 10\% FBS express low level of calponin (lane 1) that is not changed by incubation with MG132 (lane 2). Ectopic expression of Myocardin induces an increase of calponin expression (lane 3). Incubation with MG132 leads to myocardin accumulation, but reduces calponin expression (lane 4). Right panel shows the quantification of the Western blot data. 


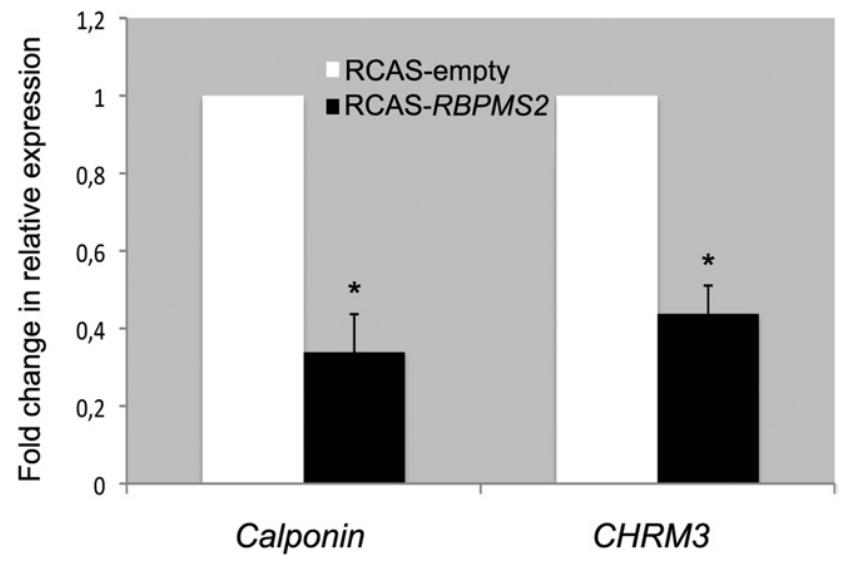

Supplementary Figure 10. Analysis of cholinergic receptor muscarinic 3 (CHRM3) and calponin mRNA expression by QPCR in primary cultured SMCs infected with RCAS-empty or RCAS-RBPMS2 retroviruses for 7 days. Normalized expression levels were converted to fold changes \pm standard deviation (RCAS-RBPMS2 vs RCAS-empty). ${ }^{*} P<$ .05. $C H R M 3$ mRNA level was decreased by $56 \%$ and calponin mRNA level by $67 \%$ in RBPMS2-overexpressing SMCs compared with control SMCs.

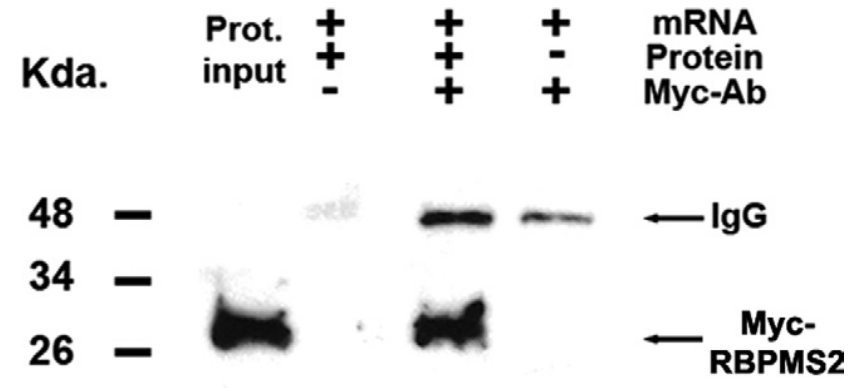

19

Supplementary Figure 12. Western blot analysis with anti-Myc antibodies after immunoprecipitation to assess the interaction between RBPMS2 and Noggin. Myc-tagged RBPMS2 in infected DF-1 cells was immunoprecipitated with anti-Myc antibodies bound to protein A Sepharose beads in the presence of total RNA from E6 chick gut. Fifty percent of beads were analyzed by Western blotting to detect Myctagged proteins. In the input and positive experiment lines a 26- kilodalton band corresponding to Myc-tagged RBPMS2 was observed.
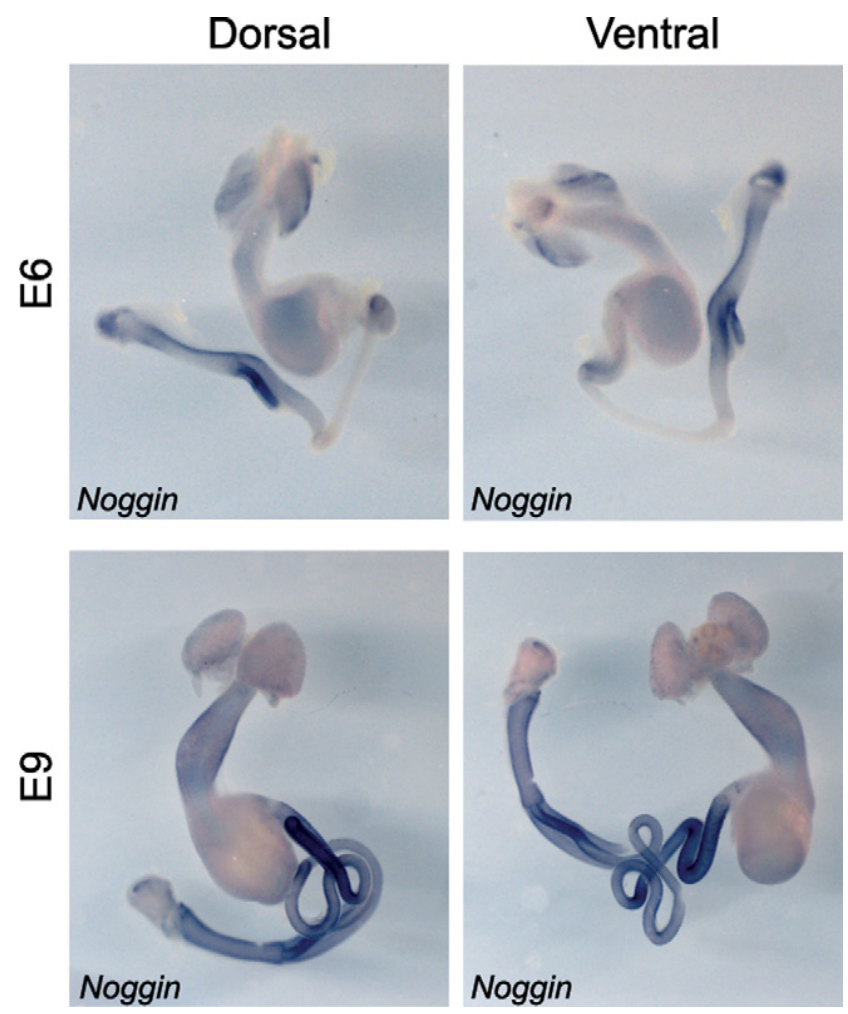

Supplementary Figure 11. Noggin expression in the chick gastrointestinal (GI) system. Whole-mount in situ hybridization of dissected E6 and $\mathrm{E} 9$ chick $\mathrm{Gl}$ tracts using an antisense riboprobe directed against Noggin. Early expression of Noggin is observed in the mesenchyme of the Gl tract at E6. 
Supplementary Table 1. Gene Specific Chick (c) Primers Used for QPCR

\begin{tabular}{lllc}
\hline Targets & \multicolumn{1}{c}{ Forward primer $\left(5^{\prime}-3^{\prime}\right)$} & \multicolumn{1}{c}{ Reverse primer $\left(5^{\prime}-3^{\prime}\right)$} & Amplicon, bp \\
\hline caSMA & CTG TAT GCT TCT GGG CG & GCA GTG GTC ACA AAG GAG & 188 \\
cCalponin & GAC GAA GGG CAA CAA CG & CAA GGG CTG GTC TGT CC & 202 \\
cSM22 & TGA GCA GGG ATG TCC AGT & AGC CAA TGA TGT TCT TGC C & 501 \\
cMyocardin & CTT CTG TCA GCA ACA CCC & AAG ACT GCG ACT GGT AAC & 300 \\
cSRF & CAG GCA CCA CAG CAA AC & CAG CCG AGA CTG GGA TT & 328 \\
cNoggin & ACC CGG ACC CTA TCT TTG & CAG CCC GTC GTA GAA CTC & 218 \\
cUbiquitin & GGG ATG CAG ATC TTC GTG AAA & CTT GCC AGC AAA GAT CAA CCT T & 147 \\
cKLF4 & GCT GCG GAT GGA AGT TTG & GCT GGC ACT GGA AAG GG & 84 \\
cFHL2 & TAC AAA CCA ATC AGT GGT C & TTC AGG GCA GAG GAT GTC A & 151 \\
cCHIP & TCG ACT TCT TCC TGG GGC & ACT GGA GCT TGG TTG ATC CG AAA CTG TTA & 193 \\
cFOXO4 & AGC CGA ACT CTT CTG CTT CTA & ATG ATA GGT TCA CTT AGA AAC TGG A & 180 \\
cCHRM3 & ACT TAC ATA CAG AGC CAA ACG A & 174 \\
\hline
\end{tabular}

CHRM3, cholinergic receptor muscarinic 3. 